\title{
Modelling of inductive resonant transfer for electric vehicles
}

\section{Luca Pugi*}

DIEF (Industrial Engineering Department),

University of Florence,

Firenze, 50139, Italy

Email: Luca.pugi@unifi.it

${ }^{*}$ Corresponding author

\section{Alberto Reatti, Rosa Anna Mastromauro and Fabio Corti}

DINFO (Department of Information Engineering),

University of Florence,

Firenze, 50139, Italy

Email: alberto.reatti@unifi.it

Email: rosaanna.mastromauro@unifi.it

Email: Fabio.corti@unifi.it

\begin{abstract}
Wireless recharge of electric vehicles is an important field of research. By means of tools used for modal analysis of vibrating systems, this paper proposes an innovative approach which is applied to the study of an inductive power (IPT) transfer system with series-series compensation. One of the main advantages of the proposed approach is the possibility of an intuitive physical interpretation. Another contribution of the work is definition of a new dimensionless parameter to optimise applied load with respect to efficiency issues. Numerical and experimental results confirm the validity and feasibility of the proposed approach.
\end{abstract}

Keywords: inductive power transfer; bondgraph approach; optimisation of vibrating systems.

Reference to this paper should be made as follows: Pugi, L., Reatti, A., Mastromauro, R.A. and Corti, F. (2018) 'Modelling of inductive resonant transfer for electric vehicles', Int. J. Electric and Hybrid Vehicles, Vol. 10, No. 2, pp.131-160.

Biographical notes: Luca Pugi obtained his Master degree in 1999 at University of Florence (Italy). In 2003 discussed is $\mathrm{PhD}$ in Applied Mechanics at University of Bologna (Italy). He is currently working at University of Florence (Italy) as researcher, cooperating with several industrial and academic institutions. His didactic and research activities are focused on mechatronics and vehicle engineering. Authors of more than 150 indexed scientific works and three industrial patents, he is an Active Member of several scientific and engineering associations including IEEE, AEIT and CIFI (national association of railway engineers). 
Alberto Reatti (M'91-00 and M'13) received his Master's degree in Electronics Engineering from the University of Florence, Florence, Italy, in 1988 and the $\mathrm{PhD}$ in high-frequency resonant power converters from the University of Bologna, Bologna, Italy, 1993. After fruitful experiences in national and international research teams, he was an Associate Researcher in the Department of Electrical Engineering, Wright State University, Dayton, OH, USA in 1992, then in 1994, a Visiting Professor in the Department of Electronics, University of Siena, Siena, Italy), he joined University of Florence where is he is currently an Associate Professor in the Department of Information Engineering. He has published more than 100 indexed research papers, He also holds two patents.

Rosa Anna Mastromauro (S'05-M'10) received his MSc and PhD degrees in Electrical Engineering from the Politecnico di Bari, Bari, Italy, in 2005 and 2009, respectively. Since 2005, she has been with the Converters, Electrical Machines, and Drives Research Team, Politecnico di Bari, where she was an Assistant Professor. Currently, she is an Associate Professor at the University of Florence, Florence, Italy, and she is engaged in teaching courses in power electronics and electrical machines. Her research interests include power converters and control techniques for distributed power generation systems based on renewable energies and transportation applications. He is a Member of the IEEE Industrial Electronics Society, IEEE Power Electronics Society IEEE Industry Application Society. She is a reviewer for IEEE conference proceedings and journals.

Fabio Corti received his BS in Electronics and Telecommunications Engineering and MS Electrical and Automation Engineer from the University of Florence, Italy, in 2014 and 2016 respectively. He is currently working towards the $\mathrm{PhD}$ in Industrial Engineering in Collaboration with Magneti Marelli on wireless charging of electric vehicle. His research interest includes modelling and control of DC-DC PWM and resonant converters.

\section{Introduction}

Inductive power transfer for wireless recharge of energy storage systems has a relevant interest for many applications ranging from portable electronic devices to electric vehicles. Power density and efficiency are crucial attributes for automotive applications where most demanding specifications are involved. In particular in Table 1 some data concerning the size of some hybrid and electric vehicles are shown: it's interesting to notice that the installed energy storage capacity for pure electric cars is about 104-105 kWh and also for hybrid ones the trend for recent models is to reach about $104 \mathrm{kWh}$. Far higher installed capacities should be found on bigger vehicles, such as trucks.

The time needed to completely recharge the battery of a vehicle is quite longer respect to the refuelling of a conventional ICE solution (hours rather than about a minute). Also corresponding autonomy of electric vehicles is lower or at best comparable with respect to conventional ones. As a consequence, diffusion and management of recharge stations should be a serious logistic threat considering that their number should be roughly proportional to the mean recharge time and inversely proportional to 
vehicle autonomy. Even considering current technology improvements, the number of electric recharge points compared with current fuel pumps should be tens or hundreds of times higher.

A possible solution to this problem is a capillary installation of recharge devices in parking areas. However, considering managed electrical power and capillary diffusion over the territory, adopted solutions should be particularly robust and resilient with respect to safety, misuse by inexperienced users and vandalism. All these specifications imply the development of unmanned recharge stations with high levels of automation including remote monitoring and diagnostics.

Table 1 Some example of electric/hybrid cars and corresponding energy storage (data are taken from manufactures sites and are updated to january 2017)

\begin{tabular}{lc}
\hline Road vehicle model & Stored energy $[\mathrm{kWh}]$ \\
\hline Tesla model S & $75-100$ \\
Nissan Leaf Tekna & 30 \\
Opel Ampera-e & 80 \\
Prius Prime (2016)Plug In Hybrid & 8.8 \\
\hline
\end{tabular}

A scheme of IPT is shown in Figure 1: power is transmitted thanks to the electromagnetic coupling between an inductor/transmitter coil buried in the ground and a receiving one installed on the vehicle.

The coil integrated on the floor is just supplied by a $85 \mathrm{kHz}$ frequency current (SAE TIR J2954, 2016) and is magnetically coupled with the receiver coil, placed under the vehicle body.

The induced currents are properly rectified and adapted to the voltage and power specifications on the vehicle-side and are used to feed and recharge an on-board energy storage system.

The system can be completely automated-unmanned and integrated as a part of standard vehicle subsystems.

Optimisation and correction of the relative positioning between vehicle and recharger coils should be easily integrated in current and future evolutions of self-parking or selfdocking functionalities installed on commercial cars (Alfatihi et al., 2013; Kim et al., 2010; Jang et al., 1999).

Finally, the system offers several advantages, in particular no plugging parts and/or moving components neither direct electrical contacts are involved. Hence, it is easy to manage protections and monitoring against system degradation, misuse or vandalism. Besides no additional space is subtracted to narrow urban environment since no external encumbering components are involved.

Additional features should concern the wireless activation of the recharge station, customer identification and billing of the purchased energy, diagnostic features including positioning or additional information needed to further optimisation and monitoring of the system.

On the contrary, the main drawback is represented by efficiency that must be maximised. The amount of energy globally involved by road transportation systems is huge and, therefore, even small variations of efficiency (which would be normally considered negligible) have a high impact on the final amount of utilised $\mathrm{kWh}$ and have 
significant effects on equivalent pollution. Also efficiency is crucial for cost and size optimisation of the system considering constraints related to power density and thermal loads.

Figure 1 Inductive power transfer (IPT) for the recharge of electric vehicles, simplified scheme (see online version for colours)

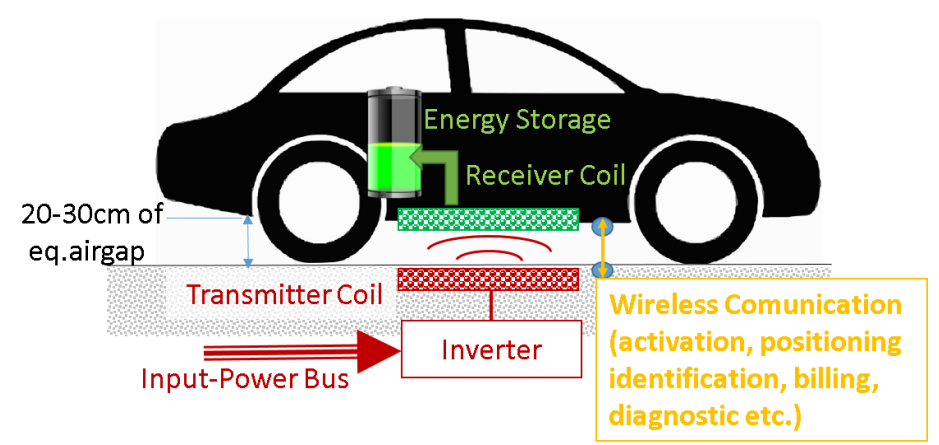

Since the distance between vehicle coil and the inductor placed under the floor cannot be lower than $20-30 \mathrm{~cm}$ the equivalent air-gap between the two coils is not negligible and, therefore, the issue of high dispersed fluxes must be faced.

To improve the mutual flux linkage, primary and secondary coils are designed to properly shape the magnetic flux. Some examples are given in the work of Budhia (Budhia et al., 2011) where ferrite elements and conductive shields are used to shape the flux flows as shown in Figure 2. Here ferrite elements offer reduced reluctance paths for induced magnetic field which is confined in a relatively small volume by shields of conductive material, typically aluminium. Multiple winding (double or multiple windings) and more complex geometries shown in Figure 3 can be adopted to improve the coupling between coils (Zicheng et al., 2016; Covic et al., 2013a).

Figure 2 Guided flux linkages in planar axial symmetric coils (see online version for colours)

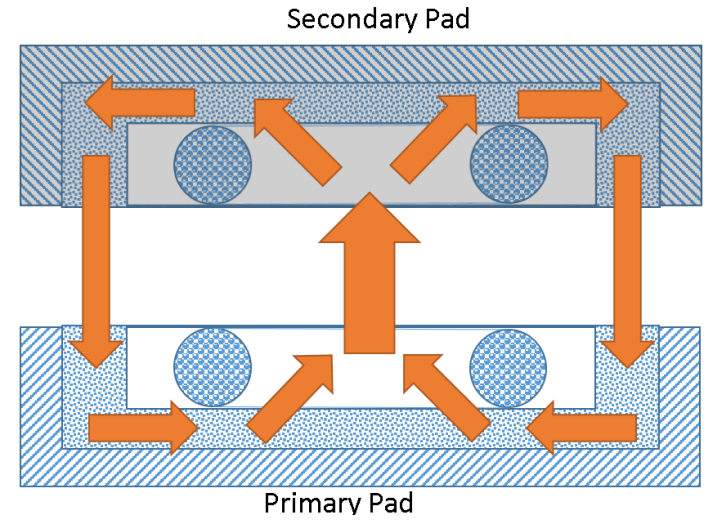

\begin{tabular}{|l|}
\hline Legend: \\
Coil \\
Ferrite \\
(ferromagnetic non \\
conductive material) \\
Shield \\
(conductive diamagnetic \\
metal) \\
Magnetic Field
\end{tabular}


Figure 3 Additional examples of coupled pads layout for inductive power transfer (see online version for colours)

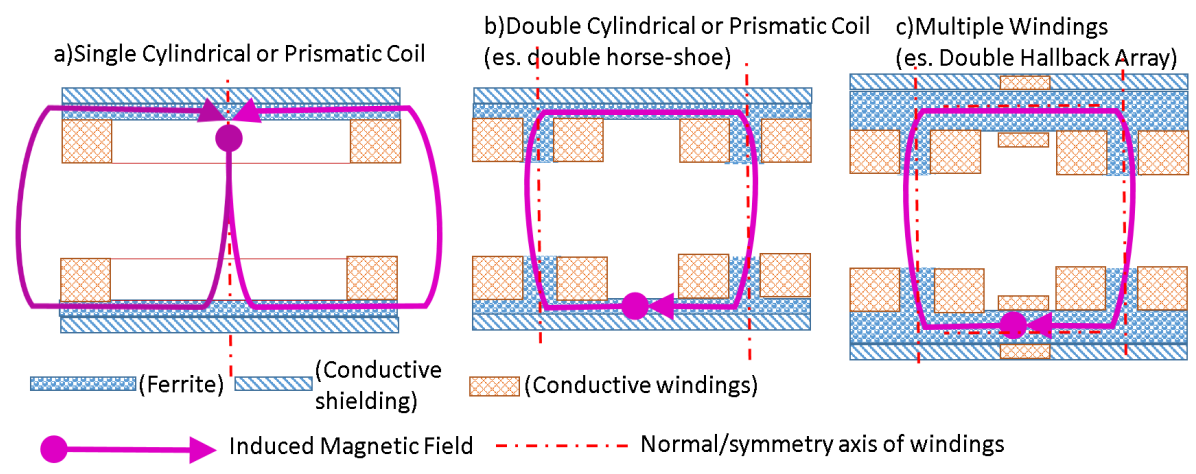

Uncertainty represents another fundamental issue in this topic. Even adopting very advanced techniques for the extraction of lumped parameters from FEM models (Xiu et al., 2016), a small percentage of parameter uncertainty cannot be avoided in the equivalent wireless power transfer magnetic circuit. Besides, the application to the automotive market involves a certain capability of the system to work in perturbed conditions in particular about the relative positioning between the two pads which is due to the parking precision, to the inflation levels of tyres or to installation tolerances of both pads on the road and on the vehicle. Finally, it is also interesting to notice that the secondary pad installed on a car should be able to work with different primary pads affected by tolerances due to different typologies, installation procedures or even suppliers (Bululukova et al., 2014)

In this work an original interpretation of the problem based on the bond-graph approach is proposed (Karnopp et al., 1990; Borutzky, 2011). Bond-graph approach is often adopted for the dynamical modelling of multi-physics systems such as steam (Pugi et al., 2015), hydraulic (Pugi et al., 2014) or pneumatic (Pugi et al., 2004) networks. Aim of the proposed approach is to provide the designer of more intuitive tools and methodologies to understand and optimise parameters affecting the sizing of the system. This is very useful especially when system parameters are uncertain or perturbed, in this cases a good comprehension of the physical behaviour of the system should be a more robust decisional support for the designer respect to pure analytical methods.

The rest of the paper is structured as follows: in Section 2 the main wireless power transfer topologies are reviewed; Section 3 deals with the equivalence between the electrical and the mechanical model; the proposed modal method for the wireless power transfer is described in Section 4; numerical and experimental results are presented respectively in Sections 5 and 6. Finally, the conclusion is given in Section 7.

\section{Wireless power transfer circuit topologies}

The number of circuit topologies usually utilised in the wireless power transfer (Zicheng et al., 2016; Covic et al., 2013a) is limited to the four shown in Figure 4. The primary coil is assumed to be fed by a $85 \mathrm{kHz}$ sinusoidal current or voltage source indicated respectively as $v_{a c}$ or $i_{a c}$. The mutual inductance $M_{12}$ between the coils is defined as: 


$$
M_{12}=k_{m} \sqrt{L_{a} L_{b}}
$$

where $k_{m}$ is the coupling or merit factor.

Figure 4 Capacitive compensation of dispersed inductances and different resonant topologies: (a) series-series compensation; (b) series-parallel compensation; (c) parallel-series compensation and (d) parallel-parallel compensation

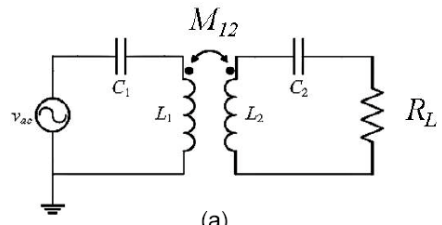

(a)

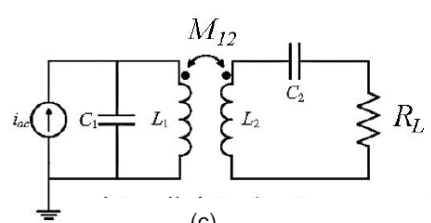

(c)

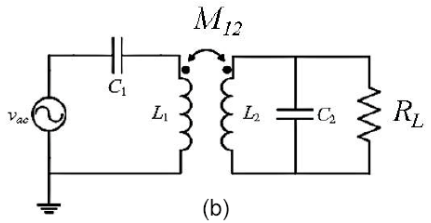

(b)

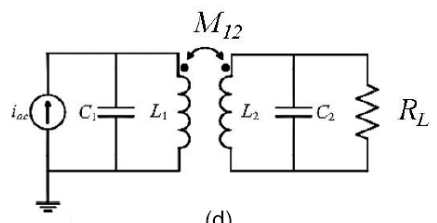

(d)
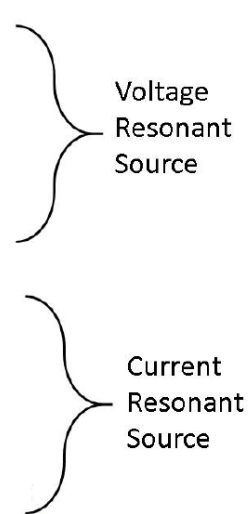

Hence, it results:

$$
\begin{aligned}
& \begin{array}{cc}
\text { mutual disp. } \\
\text { inductance } \\
\text { induct. }
\end{array} \\
& L_{a}=\overbrace{M_{12}}^{\text {inductance }}+\overbrace{L_{1}}^{\text {induct. }} \text {; } \\
& \text { mutual disp. }
\end{aligned}
$$

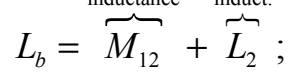

where $L_{a}$ and $L_{b}$ denote the inductances of respectively primary and secondary coils, while $L_{1}$ and $L_{2}$ denote corresponding values of dispersed ones (so their value depends by the magnetic coupling factor $k_{m}$ ).

Capacities $C_{1}$ and $C_{2}$ are inserted respectively in the primary and secondary power circuit in order to compensate the effects of the corresponding inductances $L_{a}$ and $L_{b}$. Considering the most diffused configuration which is the series-series one (Zhong and Hui, 2015; Zhao et al., 2015), the capacitors are designed in order to satisfy the following equations:

$$
\begin{aligned}
& C_{1}=\frac{1}{\omega_{A C}^{2} L_{a}} \\
& C_{2}=\frac{1}{\omega_{A C}^{2} L_{b}}
\end{aligned}
$$

where $\omega_{A C}$ is the input frequency of the circuit.

Neglecting the effect of internal resistances of the circuits, equations (3) and (4) imply that the primary coil is resonating at the input frequency. The same resonant frequency is also assumed for the secondary coupled coil. 
In this way both the circuits are tuned to resonate at the chosen input frequency obtaining good efficiency in terms of power transferred on the load $R_{L}$.

In particular, series-series configuration have been investigated (Zhong and Hui, 2015 ) in order to find the optimal sizing of the load $R_{L}$, also considering the value of the parasitic resistances of coils $R_{I}$ and $R_{2}$ according the equivalent circuit of Figure 5 .

Figure 5 Equivalent circuit for series-series compensation including coil parasitic resistances (see online version for colours)

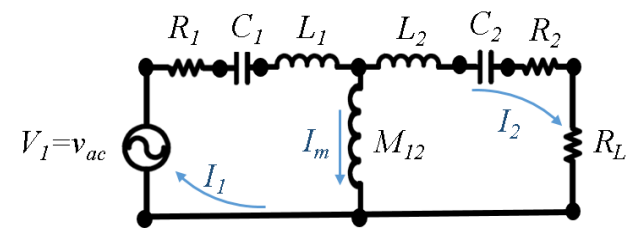

Starting from equations (3) and (4), the same authors obtained two different values of optimal loading resistance: the first one (denoted as $R_{\text {Lpow }}$, ) for the power transfer maximisation, the second one $\left(R_{L \eta}\right)$ for the efficiency maximisation.

$$
\begin{aligned}
& R_{\text {Lpow }}=\sqrt{\frac{\left(\omega_{A C}^{2} M_{12}^{2}+R_{2} R_{1}-\omega_{A C}^{2} L_{2} L_{1}\right)^{2}+\omega_{A C}^{2}\left(R_{1} L_{2}+R_{2} L_{1}\right)^{2}}{R_{1}^{2}+\omega_{A C}^{2} L_{1}^{2}}} \\
& R_{L \eta}=R_{2} \sqrt{1+\frac{\omega_{A C}^{2} M_{12}^{2}}{R_{2} R_{1}}}
\end{aligned}
$$

The above described relationships offer some criteria for the design of the system in order to properly size the main elements of both primary and secondary power circuits of the pads adopted for wireless power transfer. However, it should be also useful an extended study of the system in order to have some more general criteria for the evaluation of its behaviour not only respect to a precise design point but also respect off-design conditions. In this way, the approach proposed by authors, should be quite useful for the designer to have a general idea of the shape of the response of the system respect to some known optimal design point.

In particular, a more physically oriented approach should be also useful to analyse the robustness of the proposed solutions respect to parametric uncertainties or design variations.

It should be noticed that parametric variations of operational parameters respect to nominal ones should be a part of the system specifications considering the particular nature of the proposed application: the resonating inductor corresponding to the primary coil is a part of fixed infrastructure that should be able to be interfaced with coils installed of different vehicles. In a short term scenario, it's not feasible the idea of a monopoly of a single builder for both sub-systems and even in this case the system should be affected by uncertainties due, as example to positioning errors of the vehicle respect to the inductor. Even considering a precise/automated parking, additional positioning errors should be produced by specific vehicle features like loading conditions or tyres. 


\section{Equivalence between the electrical and mechanical models}

Bond-graph approach is based on the idea that the modelling of different physical domains, whose behaviour is described by ordinary differential equations, can be easily unified considering the physical analogy briefly summarised in Table 2 .

Table 2 Equivalence between physical domains

\begin{tabular}{|c|c|c|c|c|c|c|}
\hline Domain & $\begin{array}{c}\text { Generalised } \\
\text { flow }\end{array}$ & $\begin{array}{c}\text { Generalised } \\
\text { effort }\end{array}$ & $\begin{array}{c}\text { Generalised } \\
\text { displacement }\end{array}$ & Resistance & Inertance & Compliance \\
\hline $\begin{array}{l}\text { Mechanical- } \\
\text { Linear }\end{array}$ & $\begin{array}{c}\text { Speed } \\
v\end{array}$ & $\begin{array}{c}\text { Force } \\
\quad F\end{array}$ & $\begin{array}{l}\text { Displ. } \\
x\end{array}$ & $\begin{array}{c}\text { Damping } \\
D\end{array}$ & $\begin{array}{c}\text { Mass } \\
M\end{array}$ & $\begin{array}{c}\text { Compl. } \\
1 / K\end{array}$ \\
\hline $\begin{array}{l}\text { Mechanical- } \\
\text { Rotational }\end{array}$ & $\begin{array}{c}\text { Speed } \\
\omega\end{array}$ & $\begin{array}{c}\text { Torque } \\
T\end{array}$ & $\begin{array}{c}\text { Angle } \\
\alpha\end{array}$ & $\begin{array}{c}\text { Ang.Damp. } \\
D_{t}\end{array}$ & $\begin{array}{c}\text { Inertia } \\
J\end{array}$ & $\begin{array}{c}\text { Compl. } \\
1 / K_{t}\end{array}$ \\
\hline $\begin{array}{l}\text { Electro- } \\
\text { Magnetic }\end{array}$ & $\begin{array}{c}\text { Current } \\
I\end{array}$ & $\begin{array}{c}\text { Voltage } \\
V\end{array}$ & $\begin{array}{c}\text { Charge } \\
q\end{array}$ & $\begin{array}{c}\text { Resistance } \\
R\end{array}$ & $\begin{array}{c}\text { Inductance } \\
L\end{array}$ & $\begin{array}{c}\text { Cap. } \\
C\end{array}$ \\
\hline $\begin{array}{l}\text { Magneto- } \\
\text { Static }\end{array}$ & $\begin{array}{c}\text { Magnetic } \\
\text { flow } \\
\phi\end{array}$ & $\begin{array}{c}\text { Magneto } \\
\text { motive } \\
e_{m}\end{array}$ & & $\begin{array}{c}\text { Reluctance } \\
\mathcal{R}\end{array}$ & & \\
\hline $\begin{array}{l}\text { Heat } \\
\text { Transfer }\end{array}$ & $\begin{array}{c}\text { Entropy rate } \\
d S / d t\end{array}$ & $\begin{array}{c}\text { Temperature } \\
T\end{array}$ & & & & \\
\hline Fluid & $\begin{array}{c}\text { Flow } \\
Q\end{array}$ & $\begin{array}{c}\text { Pressure } \\
P\end{array}$ & $\begin{array}{c}\text { Volume } \\
\mathrm{V}\end{array}$ & & & \\
\hline
\end{tabular}

Source: Karnopp et al. (1990) and Borutzky (2011)

Adopting the analogy between electrical and mechanical systems that is often used in literature (Karnopp et al., 1990; Covic et al., 2013b), it is possible to model the electric system represented in Figure 5 as an equivalent 2D.O.F. (Degree Of Freedom) mechanical model of a described in Figure 6 and in Table 3.

Figure 6 Lumped mechanical system equivalent to the electrical circuit of Figure 5 (see online version for colours)

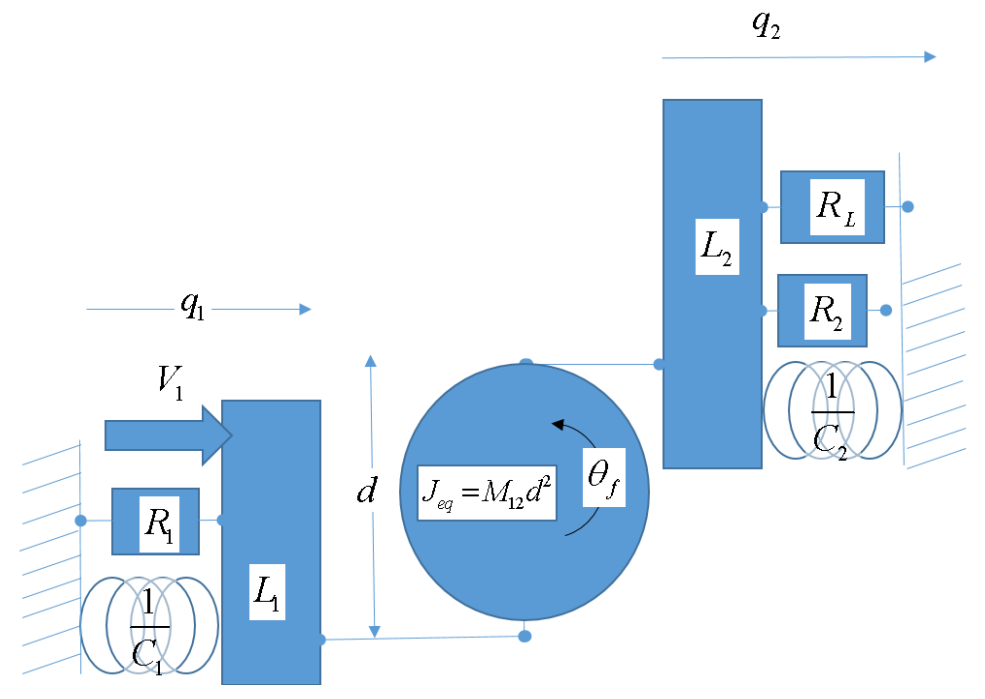


For the mechanical system, equations are written starting from the equivalence among the charges $q_{1}$ and $q_{2}$ (defined as integrals of the corresponding currents $I_{1}, I_{2}$ ), and the corresponding displacements of the mechanical systems. Following this approach, inductances, resistances and capacities should be easily treated as equivalent inertial, damping and elastic elements. The resulting system of equations describing the behaviour of the equivalent mechanical systems is:

$$
\begin{aligned}
& M \ddot{x}+D \dot{x}+K x=F \\
& x=\left[\begin{array}{l}
q_{1} \\
q_{2}
\end{array}\right] ; F=\left[\begin{array}{l}
V_{1} \\
0
\end{array}\right] ; M=\left[\begin{array}{ll}
L_{1}+M_{12} & -M_{12} \\
-M_{12} & L_{2}+M_{12}
\end{array}\right] ; D=\left[\begin{array}{ll}
R_{1} & 0 \\
0 & R_{2}+R_{L}
\end{array}\right] ; \quad K=\left[\begin{array}{cc}
\frac{1}{C_{1}} & \frac{1}{C_{2}}
\end{array}\right]
\end{aligned}
$$

where the adopted notation is in compliance with Ewins's notation (Ewins, 1994; Stephen,2006): $x$ is the vector of the adopted physical coordinates $\left(q_{1}\right.$ and $\left.q_{2}\right)$ and $M, D$ and $K$ represent respectively, the corresponding matrices of inertial, damping and stiffness terms.

Table 3 Equivalence between the electrical circuit of Figure 5 and mechanical model

\begin{tabular}{|c|c|c|c|c|}
\hline $\begin{array}{l}\text { Parameter of the } \\
\text { electrical model } \\
\text { of Figure } 5\end{array}$ & $\begin{array}{l}\text { Resistances } \\
R_{I} / R_{2} / R_{L}[\Omega]\end{array}$ & $\begin{array}{c}\text { Capacities } \\
C_{1} C_{2}[F]\end{array}$ & $\begin{array}{l}\text { Inductances } \\
L_{1} L_{2}[H]\end{array}$ & $\begin{array}{c}\text { Mutual Inductance } \\
\text { M12[H] }\end{array}$ \\
\hline $\begin{array}{l}\text { Corresponding } \\
\text { Parameter of the } \\
\text { Mechanical } \\
\text { model of } \\
\text { Figure } 6\end{array}$ & $\begin{array}{c}\text { Viscous } \\
\text { Damper with } \\
\text { viscosities } \\
R_{1} / R_{2} / R_{L} \\
{\left[\mathrm{Nsm}^{-1}\right]}\end{array}$ & $\begin{array}{l}\text { Equivalent } \\
\text { Spring with eq. } \\
\text { stiffness } \\
\text { respectively } \\
\text { equal to } 1 / C_{1} \text {, } \\
1 / C_{2}[\mathrm{~N} / \mathrm{m}]\end{array}$ & $\begin{array}{c}\text { Equivalent Mass } \\
\text { (Inertia against } \\
\text { long. motion). } \\
L_{1}, L_{2}[\mathrm{~kg}]\end{array}$ & $\begin{array}{l}\text { Equivalent rotational inertia } \\
\text { (Inertia against long. } \\
\text { motion). } \\
J_{e q}=M_{12} d^{2}\left[\mathrm{kgm}^{2}\right]^{*} \\
\text { *d is a fictitious length that } \\
\text { for the reasons described in } \\
\text { the paper text should be set } \\
\text { to } 1 \text { being: } \\
\frac{1}{2} J_{e q} \dot{\theta}_{f}^{2}=\frac{1}{2} M_{12}\left(\dot{q}_{1}-\dot{q}_{2}\right)^{2} \\
{\left[\left(\dot{q}_{1}-\dot{q}_{2}\right)^{2}=\dot{\theta}_{f}^{2} d^{2}\right]}\end{array}$ \\
\hline $\begin{array}{l}\text { Variable/State/ } \\
\text { Forcing Input of } \\
\text { the Electrical } \\
\text { Model of } \\
\text { Figure } 5\end{array}$ & $\begin{array}{c}\text { Currents } \\
\text { (States) } I_{1} I_{2}[\mathrm{~A}] \\
\text { are time } \\
\text { derivatives of } \\
\text { charges } q_{1} \text { and } \\
q_{2}[C] \text { of } \\
\text { capacitors }\end{array}$ & $\begin{array}{c}\text { Voltages } \\
\text { (Forcing Input) } \\
V_{l}[\mathrm{~V}]\end{array}$ & & \\
\hline $\begin{array}{l}\text { Corresponding } \\
\text { Variable/State/ } \\
\text { Forcing Input of } \\
\text { the Mechanical } \\
\text { model } \\
\text { of Figure } 6\end{array}$ & $\begin{array}{c}\text { Equivalent } \\
\text { displacement } q_{1} \\
\text { and } q_{2}[\mathrm{~m}] \text { or } \\
\text { speed } \\
\dot{q}_{i}=I_{i}[\mathrm{~m} / \mathrm{s}]\end{array}$ & $\begin{array}{l}\text { Equivalent } \\
\text { Force with } \\
\text { value } V_{I}[\mathrm{~N}]\end{array}$ & & \\
\hline
\end{tabular}
in Figure 6 
From equation (7) it can be also obtained the state space representation where the state vector $X$ includes not only the charges $q_{1}$ and $q_{2}$ but also their time derivatives corresponding to currents $I_{1}$ and $I_{2}$ (Zhao et al., 2015),

$$
\begin{aligned}
& \dot{X}=A X+B u \\
& X=\left[\begin{array}{c}
x \\
\dot{x}
\end{array}\right]=\left[\begin{array}{c}
q_{1} \\
q_{2} \\
\dot{q}_{1} \\
\dot{q}_{2}
\end{array}\right] ; u=F=\left[\begin{array}{c}
V_{1} \\
0
\end{array}\right] ; A=\left[\begin{array}{cccc}
0 & 0 & 1 & 0 \\
0 & 0 & 0 & 1 \\
-M^{-1} K & -M^{-1} D
\end{array}\right] ; B=\left[\begin{array}{ll}
0 & 0 \\
0 & 0 \\
1 & 0 \\
0 & 1
\end{array}\right] ;
\end{aligned}
$$

\section{Proposed modal approach}

\subsection{System response in case of proportional damping}

By calculating eigen-vectors and eigen-values of the A matrix (8), it is possible to calculate the corresponding modes $\psi_{i}$ and frequencies $\omega_{n i}$ of the system considering that the number of calculated modes and frequencies depends on the number of degrees of freedom of the system. Since the system has only two degrees of freedom, the matrix $\psi$ is a $4 \times 4$ one and its columns are respectively composed by the two modes $\psi_{1}, \psi_{2}$ and by their conjugates $\psi *_{1}, \psi *_{2}$.

If the damping matrix $D$ can be expressed as a linear combination of $M$ and $K$ ones, the "proportional damping" hypothesis is verified:

$$
D=\alpha M+\beta K
$$

If proportional damping is verified, calculated modes are invariant with respect to the damping and are equal to the ones calculated for the un-damped system $\left(R_{I}=R_{2}=R_{L}=0\right)$. In this case modes $\psi_{i}$ can be calculated from the eigenvectors $\varphi_{1}$ and $\varphi_{2}$ of the matrix corresponding to the product $M^{-1} K$.

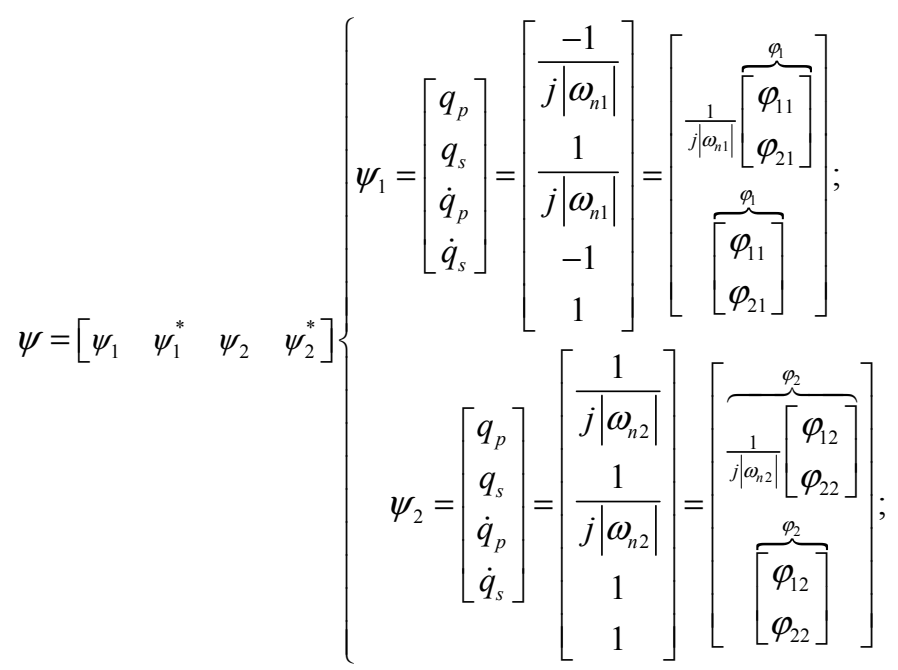


If proportional damping is verified all coefficients of the $\varphi_{i}$ vectors are real numbers.

If the primary and secondary windings are equal $\left(L_{1}=L_{2} ; C_{l}=C_{2} ; R_{l}=R_{2}\right)$ and no load $\left(R_{L}=0\right)$ or constant voltage load is applied (constant $\left.V_{L}=V_{2}\right)$, the calculated eigen-values of $\mathrm{A}$ are described by:

$$
\omega_{n}=\left[\begin{array}{c}
\omega_{n 1} \\
\omega_{n 2}
\end{array}\right]=\left[\begin{array}{l}
\sqrt{\frac{-1-\sqrt{1-4 C_{1}^{2} L_{1} R_{1}-8 C_{1}^{2} M_{12} R_{1}}}{2\left(2 C_{1} M_{12}+C_{1} L_{1}\right)}} \\
\sqrt{\frac{-\sqrt{-4 C_{1}^{2} L_{1} R_{1}+1}}{2 C_{1} L_{1}}-\frac{1}{2 C_{1} L_{1}}}
\end{array}\right]
$$

Looking at the solution of the un-damped system $\left(R_{1}=R_{2}=R_{L}=0\right)$ with equal coils ( $L_{a}=L_{b}, L_{l}=L_{2}, C_{l}=C_{2}$ ), it is clearly advisable the effect of the figure of merit $k_{m}$ : with loosely coupled windings (low values of $k_{m}$ ) the value of $\omega_{n 1^{*}}$ converges to the value of $\omega_{n 2}$. The sub-index* is introduced to indicate the eigen-frequency of the un-damped system.

$$
\begin{aligned}
& k_{m}=\frac{M_{12}}{\sqrt{L_{a} L_{b}}}=\frac{M_{12}}{\sqrt{\left(M_{12}+L_{1}\right)\left(M_{12}+L_{2}\right)}} \text { if }\left(L_{a}=L_{b}\right) \Rightarrow k_{m}=\frac{M_{12}}{L_{a}}=\frac{M_{12}}{\left(M_{12}+L_{1}\right)} \\
& \omega_{n 1^{*}}=j \sqrt{\frac{1}{2 C_{1} M_{12}+C_{1} L_{1}}}=j \sqrt{\frac{1}{C_{1} L_{a}\left(1+k_{m}\right)}} ; \omega_{n 2^{*}}=j \sqrt{\frac{1}{C_{1} L_{1}}}=j \sqrt{\frac{1}{C_{1} L_{a}\left(1-k_{m}\right)}} \\
& \text { for } k_{m} \rightarrow 0 \Rightarrow \omega_{n 1^{*}}=\omega_{n 2^{*}}=j \sqrt{\frac{1}{C_{1} L_{a}}} \cong j \sqrt{\frac{1}{C_{1} L_{1}}}
\end{aligned}
$$

Maintaining the same simplifications assumed for (11), it is also possible to calculate both the eigen-frequencies $\omega_{n i}$ of the damped system respect to $\omega_{n i}$ the ones of the undamped one (13):

$$
\omega_{n i}=-\xi_{i}\left|\omega_{n i^{*}}\right|+j\left|\omega_{n i^{*}}\right| \sqrt{1-\xi_{i}^{2}}
$$

In equation (13) it's introduced $\xi_{i}$, a dimensionless coefficient usually defined in modal analysis as "damping factor of the of the $i$ th mode (Ewins, 1984)". The mode describes the "shape" of the solution associated to eigen-frequency $\omega_{n i}$.

In order to calculate the damping factor $\xi_{i}$ associated with each mode, the system (7) should be rewritten with respect to modal coordinates $x_{\varphi}$ which are defined with respect to the physical coordinates $x$ through the modal transformation matrix $\varphi$ (columns of the matrix are the modes $\varphi_{i}$ of the system). The resulting system is described in equation (14):

$$
\begin{aligned}
& M_{\varphi} \ddot{x}_{\varphi}+D_{\varphi} \dot{x}_{\varphi}+K_{\varphi} x_{\varphi}=F_{\varphi} ; \quad M_{\varphi}=\varphi^{t} M \varphi ; \quad K_{\varphi}=\varphi^{t} K \varphi ; \\
& D_{\varphi}=\varphi^{t} K \varphi ; \quad F_{\varphi}=\varphi^{t} F ; \quad x=\varphi x_{\varphi} \Rightarrow x_{\varphi}=\varphi^{-1} x ;
\end{aligned}
$$

The adoption of modal coordinates involves several interesting properties for system (14): with respect to this new system of coordinates, the resulting matrixes of inertia $M_{\varphi}$ and stiffness $K_{\varphi}$ are diagonals. Also the damping one, $D_{\varphi}$ (in case of proportional damping) is also diagonal, since it should be expressed as a linear combination of inertia 
and stiffness ones. As a consequence, each single differential equation/row of system (14) is completely decoupled with respect to the other ones and it can be solved separately from the other ones as a single degree of freedom system.

So, by rewriting the model with respect to modal coordinates, a generic system with an arbitrary number of degrees of freedom should be represented and solved as an array of decoupled SDOF ones (Single Degree of Freedom) for which there is a wide and consolidated literature (Ewins, 1984; Fu, 2001; Shabana, 1996). It's quite important to notice that in case of proportional damping, modal shapes and the matrix $\varphi$ are invariant with respect to the variations of the damping matrix: as a consequence, adopted system of modal/principal coordinates is not affected by variations of applied viscous-resistive loads if proportional damping conditions is still respected.

Finally it should be demonstrated (Ewins, 1984; Fu, 2001; Shabana, 1996) that all the coefficients of the matrix $\varphi$ are real (e.g., not complex) numbers, making easier the comprehension of corresponding modal shapes: in particular, in this case, position of nodes of modal shapes is stationary (normal or stationary modal shapes) while in case of modes with complex coefficients also the position of nodes of the modal shapes should be time variant ("propagating modal shapes") making less intuitive the corresponding interpretation and representation of the solution.

As previously said, system (14) is completely decoupled, the corresponding damping factor $\xi_{i}$ of the $i$ th mode can be easily calculated as the one of the corresponding SDOF system (15) whose dynamic is described by the $i$ th row of equation (14):

$$
\begin{aligned}
& \xi_{i}=\frac{D_{\varphi_{-} i i}}{2 \sqrt{K_{\varphi_{-} i i} M_{\varphi_{-} i i}}} \\
& \xi_{1}=\frac{R_{1}}{\sqrt{\frac{2 M_{12}+L_{1}}{C_{1}}}}=\frac{R_{1}}{\sqrt{\frac{L_{a}\left(1+k_{m}\right)}{C_{1}}}} ; \quad \xi_{2}=\frac{R_{1}}{\sqrt{\frac{L_{a}\left(1-k_{m}\right)}{C_{1}}}} ;
\end{aligned}
$$

For the decoupled system (14), it can be also calculated the magnification factor $\beta_{i}$ of each mode which is defined as the ratio in modal coordinates between the displacement at the current excitation frequency $\omega$ and the corresponding static one. $\beta_{i}$ is usually defined as a function of $r$ which denotes the ratio between the forcing sinusoidal frequency and the corresponding un-damped natural frequency $\omega_{n 1 *}$.

$$
\begin{aligned}
& \beta_{i}(\omega)=\frac{1}{\sqrt{\left(1-r^{2}\right)^{2}+2(r \varepsilon)^{2}}}=\frac{1}{\sqrt{\left(1-\left(\frac{\omega}{\omega_{n i^{*}}}\right)^{2}\right)^{2}+2(r \varepsilon)^{2}}} ; r=\frac{\omega}{\omega_{n i^{*}}} \\
& \omega_{r i}=\omega_{n i *} \sqrt{1-2 \xi_{i}^{2}} \\
& \beta_{\text {max } \__{-}}=\frac{1}{2 \xi \sqrt{1-\xi^{2}}}
\end{aligned}
$$

The forced response represented in terms of $\beta_{i}$ is maximised when the exciting frequency is equal to the resonance frequency $\omega_{r i}$ (17) being $\beta_{M A X_{-} i}$ (18) the corresponding maximum of the mode amplification factor: 
More generally $\omega_{n i}$ are also poles of the transfer input matrix from voltage inputs $u$ to systems states $X$ that can be easily calculated according to:

$$
\frac{X}{u}=(s I-A)^{-1} B
$$

If the simplifying hypothesis of proportional damping is not verified, finding an equivalent closed form solution results is difficult. However numerical solutions can be easily handled considering the small size of the involved matrices.

\subsection{Approximated response with non-proportional damping}

In the previous sections authors have introduced the typical approach that is used by mechanical engineers to perform modal analysis, which should be summarised in the following points:

- It's possible to rewrite the system of ordinary differential equations (ODE) that describe the dynamical behaviour of the model, with respect to particular coordinates, the modal ones: with respect to this new coordinates each differential equation is decoupled with respect to the other ones and it should be solved separately.

- In case of proportional damping, modal coordinates are invariant with respect to applied viscous effects.

For the purpose of investigating an IPT system the hypothesis of proportional damping is only approximately verified. In particular, referring to the scheme of Figure 5, it's feasible that internal resistances of coils $R_{I}$ and $R_{2}$ are quite small and approximately proportional to inductances $L_{1}$ and $L_{2}$, so for unloaded coils $\left(R_{L}=0\right)$ the hypothesis of proportional damping should be verified. Unfortunately, high efficiencies and high power transfers should be associated to relatively high values of the resistive loads $R_{L}$ respect to $R_{1}$ and $R_{2}$. In this case, which is the most common with respect to industrial applications the damping matrix cannot be expressed as linear combination of $M$ and $K$.

However, IPT resonating circuits cannot be too much damped since their principle of operation is substantially based on the amplification/magnification of the exciting voltage applied on the primary coils: in order to maximise power transfer the value of the load $R_{L}$ has to be appreciable respect to $R_{1}$ and $R_{2}$ but not too high since a relatively high current on the secondary coil has to be maintained.

As a consequence, a typical IPT system should be modelled as a modestly damped circuit.

Response of a generic lightly damped system should be studied considering an equivalent approximating system which respect the hypothesis of proportional damping. In this way all the above described simplifications which are valid in case of proportional damping should be applied.

In particular, the damping matrix $D$ should be decomposed as the sum of two submatrices, the first one $D_{p}$ which satisfies condition (9) and a second one $D_{n}$ containing the corresponding residual damping terms as visible in (20).

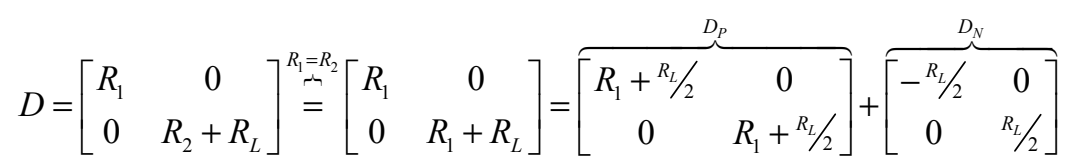


From matrices $D_{P}$ and $D_{N}$ which represent system damping with respect to physical coordinates $x$, it's possible to re-calculate the corresponding matrices $D_{\varphi P}$ and $D_{\varphi N}$ expressed with respect to principal ones $x_{\varphi}(21)$.

$$
\begin{aligned}
& D_{\varphi}=\varphi^{t} D \varphi=\varphi^{t}\left(D_{P}+D_{N}\right) \varphi= \\
& =\overbrace{\left[\begin{array}{cc}
2 R_{1}+R_{L} & 0 \\
0 & 2 R_{1}+R_{L}
\end{array}\right]+\overbrace{\left[\begin{array}{cc}
0 & R_{L} \\
R_{L} & 0
\end{array}\right]}^{D_{\rho \rho}}}^{D_{\rho \mathcal{N}}}
\end{aligned}
$$

The contribution of the matrix $D_{\varphi N}$. is neglected and the system is approximately studied with respect to principal coordinates considering only the part of damping, $D_{\varphi P}$ for which the proportionality hypothesis (9) is verified.

Considering the above described simplifications the system should be approximately studied by exploiting the properties of a two degrees of freedom with proportional damping: in this case, for each of the two modes, the corresponding damping factors $\xi_{1}$ and $\xi_{2}$ should be calculated according (22):

$$
\xi_{1}=\frac{R_{1}+R_{L} / 2}{\sqrt{\frac{L_{a}\left(1+k_{m}\right)}{C_{1}}}} ; \quad \xi_{2}=\frac{R_{1}+R_{L} / 2}{\sqrt{\frac{L_{a}\left(1-k_{m}\right)}{C_{1}}}} ;
$$

In the proposed application the excitation is represented by the input voltage of the primary coil $V_{l}$, that should be decomposed in the corresponding principal components according to equation (23):

$$
F_{\varphi}=\varphi^{t} F=\left[\begin{array}{l}
V_{2}-V_{1} \\
V_{1}+V_{2}
\end{array}\right]
$$

If the damping factors $\xi_{1}$ and $\xi_{2}$ are relatively low (low values of $R_{L}$ ), the two modes should be excited separately and cross interactions between modes are quite negligible considering a single frequency-sinusoidal input.

In this hypothesis the maximum power is transferred when the resonant frequency of the mode is excited. In this case the power transferred to the load $W_{L}$ can be approximately calculated as (24):

$$
\frac{W_{L}}{V_{1}^{2}}\left(\omega_{r i}\right) \approx R_{L} C_{1}^{2} \beta_{i}^{2}\left(\omega_{r i}\right) \omega_{r i}^{2} \approx \frac{R_{L}}{4\left(R_{1}+R_{L} / 2\right)^{2}}
$$

From equation (24) it should be observed that maximum transferred power is weakly or not affected by the coupling factor $k_{m}$ when only one lightly damped mode is directly excited.

Considering above described hypothesis, the totally absorbed power $W_{l}$ can be approximated by equation (25):

$$
\frac{W_{1}}{V_{1}^{2}}\left(\omega_{r i}\right) \approx\left(R_{L}+2 R_{1}\right) C_{1}^{2} \omega_{n^{*}}^{2} \beta_{i}^{2} \approx \frac{R_{L}+2 R_{1}}{4\left(R_{1}+R_{L} / 2\right)^{2}}
$$


As a consequence, the efficiency corresponding to the separated excitation of the two modes results:

$$
\eta_{i}=\frac{W_{L}}{W_{1}} \approx \frac{R_{L}}{R_{L}+2 R_{1}}
$$

Equations (24)-(26) are approximately valid if the input frequency of the voltage excites only one mode and, more generally, the two modes are lightly damped and well separated. This last condition (lightly damped and well separated modes) should be assured valid if the index $k_{s}$ (mean frequency weighted damping factor) is far lower than one, where $k_{s}$ is defined as equation (27):

$$
k_{s}=\frac{\varepsilon_{1} \omega_{n 1^{*}}+\varepsilon_{2} \omega_{n 2^{*}}}{\omega_{n 2^{*}}-\omega_{n 1^{*}}}=\frac{2\left(R_{1}+R_{L} / 2\right)}{\sqrt{\frac{L_{a}}{C_{1}}\left(1-k_{m}^{2}\right)}\left(\sqrt{1+k_{m}}-\sqrt{1-k_{m}}\right)}<<1
$$

Equation (27) is obtained through some approximations from the 'half power method' [19] which is a commonly used to correlate the damping factor of a mode respect to the shape of its forced frequency response function.

The approximated relationship between the damping factor of the mode $\xi_{i}$ and the corresponding interval $\left|\Delta \omega_{\mathrm{i}}\right|$ at which the forced response is about three decibel lower respect to the peak one is described by the following equation (28) and by Figure 7

$$
\begin{aligned}
& 2 \xi_{i} \approx \frac{\left|\Delta \omega_{i}\right|}{\omega_{n i^{*}}} \Rightarrow \xi_{i} \approx \frac{\left|\omega_{h b_{-} i}-\omega_{n i^{*}}\right|}{\omega_{n i^{*}}} \approx \frac{\left|\omega_{h a_{-} i}-\omega_{n i^{*}}\right|}{\omega_{n i^{*}}} \\
& \left|\Delta \omega_{i}\right|=\left|\omega_{h_{-} b_{-} i}-\omega_{h_{-} a_{-} i}\right|
\end{aligned}
$$

where $\omega_{h a_{-} i}$ and $\omega_{h b_{-} i}$ denote the two 'half power' frequencies.

Figure 7 Half power method, approximated relationship between damping factor and forced frequency response (see online version for colours)

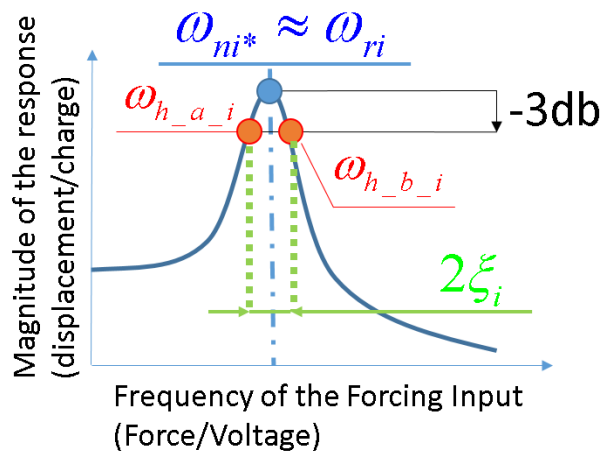

Equations (24)-(26) are referred to a design of the system which is based on the excitation of a single mode. However it is possible to define a value of the forcing input frequency, denoted as $\omega_{\text {opt }}$ (29) for which the amplification factors of the two modes $\beta_{1}\left(\omega_{\text {opt }}\right)$ and $\beta_{2}\left(\omega_{\text {opt }}\right)$ have the same value (30) independently from the value of $k_{m}$. 


$$
\begin{aligned}
& \omega_{\text {opt }}=\sqrt{\frac{1}{C_{1} L_{a}}} \\
& \left|\beta_{1}\left(\omega_{\text {opt }}\right)\right|=\left|\beta_{2}\left(\omega_{\text {opt }}\right)\right|=\frac{1}{\sqrt{k_{m}^{2}+2 \frac{C_{1}}{L_{a}}\left(R_{1}+R_{L} / 2\right)^{2}}}
\end{aligned}
$$

It can be noticed that equation (30) is obtained neglecting, as previously said, the contribution of the non-proportional part of the damping represented by the damping matrices $D_{N}(20)$ and $D_{\varphi N}(21)$. As a consequence, equation (30) is an approximation of the real behaviour of the system.

The response of the system in terms of receptance functions can be rewritten according to equation (31):

$$
\begin{aligned}
& \alpha_{j k}(\omega)=\sum_{r=1}^{2} \frac{\varphi_{j r} \varphi_{k r}}{\left(-\omega^{2} m_{\varphi r}+k_{\varphi r}\right)+j\left(\omega d_{\varphi P r}\right)} \\
& M_{\varphi}=\varphi^{t} M \varphi=\left[\begin{array}{cc}
m_{\varphi 1} & 0 \\
0 & m_{\varphi 2}
\end{array}\right]=\left[\begin{array}{cc}
2 L_{a}\left(1+k_{m}\right) & 0 \\
0 & 2 L_{a}\left(1-k_{m}\right)
\end{array}\right] ; \\
& K_{\varphi}=\varphi^{t} K \varphi=\left[\begin{array}{cc}
k_{\varphi 1} & 0 \\
0 & k_{\varphi 2}
\end{array}\right]=\left[\begin{array}{cc}
\frac{2}{C_{1}} & 0 \\
0 & \frac{2}{C_{1}}
\end{array}\right] ; D_{\varphi P}=\varphi^{t} D_{P} \varphi=\left[\begin{array}{cc}
d_{\varphi P 1} & 0 \\
0 & d_{\varphi P 1}
\end{array}\right]=\left[\begin{array}{cc}
2 R_{1}+R_{L} & 0 \\
0 & 2 R_{1}+R_{L}
\end{array}\right] ;
\end{aligned}
$$

where $M_{\varphi}, K_{\varphi}$ and $D_{\varphi P}$ denote the diagonalised matrices obtained from $M, K$ and $D_{\varphi P}$.

In particular it should be interesting to calculate the transfer function $\alpha_{21}$ between the input voltage $V_{l}$ and the corresponding output on the secondary coil: since receptance is considered, the output is the charge $q_{2}$, for the calculations of currents it should be considered the mobility transfer functions; however mobility for a system forced with a sinusoidal input, is equal to the product of the corresponding receptance $\alpha_{i j}$ for the exciting frequency. So, as it should be clear, in the next paragraphs the same calculations concerning power transfer and efficiency should be performed both considering receptance or modal mobility transfer functions.

If the input frequency $\omega_{A C}$ is equal to $\omega_{\text {opt }}\left(\omega_{\text {opt }}=\omega_{A C}\right), \alpha_{21}\left(\omega_{\text {opt }}\right)$ should be described by equation (32): it's interesting to notice that the response of the system is equal to the sum of two terms each corresponding to the excitation of one of the two modes: it's interesting to notice that this two component of the response corresponds to a couple of conjugated complex numbers so corresponding phasors should be in quadrature having the same module.

$$
\alpha_{21}\left(\omega_{o p t}\right)=\overbrace{\frac{1}{\frac{2 k_{m}}{C_{1}}-j \frac{\left(2 R_{1}+R_{L}\right)}{\sqrt{C_{1} L_{a}}}}}^{C_{1} \beta_{1}\left(\omega_{o p t}\right)}+\overbrace{\frac{1}{\frac{2 k_{m}}{C_{1}}+j \frac{\left(2 R_{1}+R_{L}\right)}{\sqrt{C_{1} L_{a}}}}}^{C_{1} \beta_{2}\left(\omega_{o p t}\right)}=\frac{\frac{4 k_{m}}{C_{1}}}{\frac{4 k_{m}^{2}}{C_{1}^{2}}-\frac{\left(2 R_{1}+R_{L}\right)^{2}}{L_{a} C_{1}}}
$$

Same approach should be extended to the calculation (33) of the receptance function $\alpha_{11}\left(\omega_{\text {opt }}\right)$ between input voltage $V_{l}$ and corresponding output on the primary coil: also in this case system response is composed by the sum of two equal phasors in quadrature. 
Their sum which represent the corresponding response on the primary coil is in quadrature respect to $\alpha_{21}\left(\omega_{\text {opt }}\right)$. The corresponding phasors of currents $I_{l}\left(\omega_{\text {opt }}\right)$ and $I_{2}\left(\omega_{\text {opt }}\right)$ are shown in Figure 8:

$$
\alpha_{11}\left(\omega_{o p t}\right)=\frac{-1}{\frac{2 k_{m}}{C_{1}}-j \frac{\left(2 R_{1}+R_{L}\right)}{\sqrt{C_{1} L_{a}}}}+\frac{1}{\frac{2 k_{m}}{C_{1}}+j \frac{\left(2 R_{1}+R_{L}\right)}{\sqrt{C_{1} L_{a}}}}=\frac{-2 j \frac{\left(2 R_{1}+R_{L}\right)}{\sqrt{C_{1} L_{a}}}}{\frac{4 k_{m}^{2}}{C_{1}^{2}}-\frac{\left(2 R_{1}+R_{L}\right)^{2}}{L_{a} C_{1}}}
$$

From equation (33) it is clearly noticeable the advantage of exciting the system at the frequency $\omega_{\text {opt }}$ : since the two modes in quadrature are excited at the same time, the corresponding output should be relatively higher. This property is clearly verified only when the exciting frequency is equal to $\omega_{\text {opt }}$ for a generic value of the input frequency $\omega$ of $V_{1}$ (different from $\omega_{\text {opt }}$ ). The two contributions of the functions $\alpha_{21}(\omega) \alpha_{11}(\omega)$ corresponding to the separated contributions of the two modes are not in quadrature as visible in the scheme of Figures 8 and 9. Hence the proposed modal approach gives to the designer important tools to qualitatively foresee the behaviour of the system with respect to dimensionless parameters such as system eigen-frequencies modal shapes (modes), and more application related factors such as $k_{s}$ and $k_{m}$.

Knowing both $\alpha_{21}\left(\omega_{\text {opt }}\right) \alpha_{11}\left(\omega_{\text {opt }}\right)$ is then possible to evaluate the efficiency $\eta\left(\omega_{\text {opt }}\right)$.

$$
\eta\left(\omega_{o p t}\right) \frac{R_{L} \alpha_{21}^{2}}{R_{1} \alpha_{11}^{2}+\left(R_{L}+R_{1}\right) \alpha_{21}^{2}}=\frac{R_{L}\left(\frac{4 k_{m}}{C_{1}}\right)^{2}}{4 R_{1} \frac{\left(2 R_{1}+R_{L}\right)^{2}}{C_{1} L_{a}}+\left(R_{L}+R_{1}\right)\left(\frac{4 k_{m}}{C_{1}}\right)^{2}}
$$

Hence it is possible to calculate an optimal value of $R_{L}, R_{\text {Lopt }}$ able to maximise the efficiency $\eta$, reaching the maximum value $\eta_{\max }$ :

$$
\begin{aligned}
& R_{\text {Lopt }}=2 \sqrt{\frac{\left(C_{1} R_{1}^{2}+L_{a} k_{m}^{2}\right)}{C_{1}}}=2 \sqrt{R_{1}^{2}+\frac{L_{a} k_{m}^{2}}{C_{1}}}=2 R_{L \eta} \\
& \eta_{\max }=\frac{L_{a} k_{m}^{2} \sqrt{C_{1}\left(C_{1} R_{1}^{2}+L_{a} k_{m}^{2}\right)}}{\left(C_{1} R_{1}^{2}+L_{a} k_{m}^{2}\right)\left(C_{1} R_{1}+\sqrt{C_{1}\left(C_{1} R_{1}^{2}+L_{a} k_{m}^{2}\right)}\right)}
\end{aligned}
$$

It results that the value of $R_{\text {Lopt }}$ is exactly double the corresponding value $R_{L \eta}$ which is calculated maximising the efficiency of the full system without proportional damping hypothesis.

Equations (35) and (36) have limited value in terms of usability and also the corresponding physical interpretation of results is quite difficult. Besides it should be considered that the optimal working condition corresponding to equations (35) and (36) has been obtained studying an approximated system with proportional damping. It should be more useful to apply directly the corresponding exact value of $R_{L \eta}$. 
Figure 8 Phasor currents $I_{l}\left(\omega_{\text {opt }}\right)$ and $I_{2}\left(\omega_{\text {opt }}\right)$ when the input frequency is equal to $\omega_{\text {opt }}$ (see online version for colours)
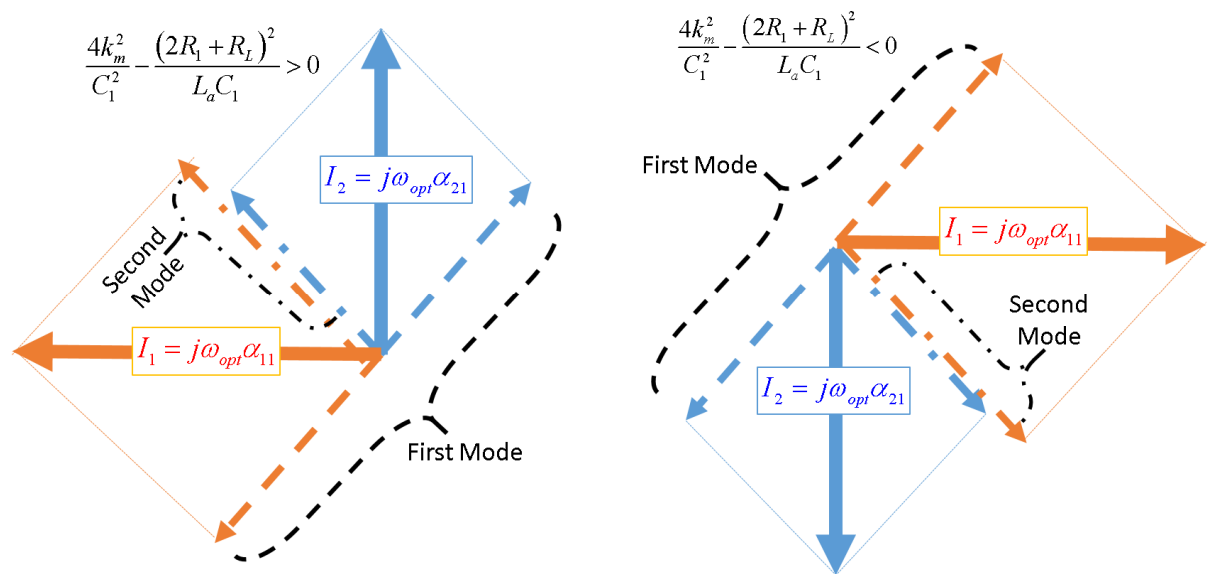

Figure 9 Phasor currents $I_{l}(\omega)$ and $I_{2}(\omega)$ approximated behaviour of the solution reconstructed with the proposed modal approach and corresponding considerations in terms of expected design features and performances (see online version for colours)

Increasing frequency $\omega$ of the Input $V_{1}$

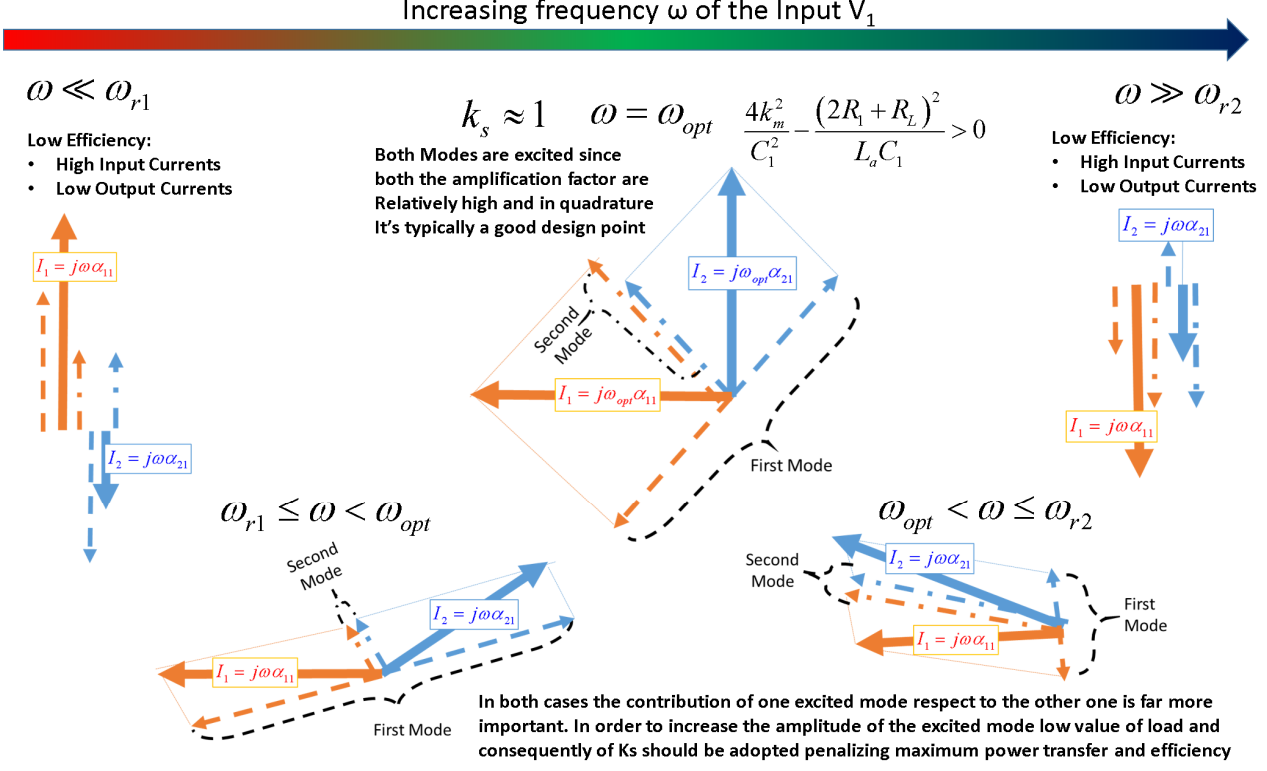

For practical application the evaluation of the dimensionless factor $k_{s}$ should be much more useful. In particular, if the value of $k_{s}$ is approximately equal to one, the input frequency $\omega_{\text {opt }}$ approximately corresponds to a half power one for both system modes. As a consequence, the corresponding output in terms of output current $I_{2}$ should be $2^{0.5}$ times higher respect to the peak one that should be obtained by directly exciting a single resonant frequency. Since the output power is proportional to the squared value of $I_{2}$ its 
value should be doubled with respect to the condition in which a single resonance frequency is excited (input frequency equal to one of the two eigen-frequencies of the system).

As a consequence, it's advisable to excite the system with an input frequency equal to $\omega_{\text {opt }}$ and a value of the load resistance $R_{L}$ corresponding to a unitary value of $k_{s}$ since in these conditions the power transferred by the sum of the two components $\left(C_{l} \beta_{l}\left(\omega_{\text {opt }}\right)\right.$, $\left.C_{l} \beta_{2}\left(\omega_{\text {opt }}\right)\right)$ of $\alpha_{21}\left(\omega_{\text {opt }}\right)$ should be relatively high. On the other hand, a further increase of $R_{L}$ and, consequently, a value of $k_{s}$ higher than one should not be advisable since high values of damping factors produce a drastic reduction of both modal amplification factors $\beta_{i}$ and consequently of the response transfer function $\alpha_{21}\left(\omega_{\text {opt }}\right)$.

From previous considerations it should be concluded that a near to optimal and robust design procedure for the considered IPT topology should involve the following steps:

- Design inductor pads in order to maximise coil inductance respect to resistance (minimising internal losses and verifying possible thermal limits) and respect to assigned specifications in terms of encumbrances, privileging configurations which maximise the mutual magnetic coupling factor $k_{m}$.

- Tune the compensating capacitors in order to assure the identity between applied excitation frequency on coils and the frequency $\omega_{\mathrm{opt}}$

- Adjust equivalent load resistances in order to be able work with a near to unitary value of $k_{s}$

According to the definition of $k_{s}$, the predicted load $R_{L K S}$ corresponding to an unitary value of $k_{s}$ can be calculated according to equation (37):

$$
R_{L K S}=\sqrt{\frac{L_{a}}{C_{1}}\left(1-k_{m}^{2}\right)}\left(\sqrt{1+k_{m}}-\sqrt{1-k_{m}}\right)-2 R_{1}
$$

Relation (37) provides numerically acceptable results only for relatively small values of $R_{l}$ and $k_{m}$. Both these conditions are usually verified since, considering typical industrial applications values of $k_{m}$. are typically lower than one. Also, as previously said resistance $R_{l}$ is usually minimised during the design of the coil.

On the other hand, it is possible to define $k_{\text {sopt }}$ and $k_{S L \eta}$ as values of $k_{s}$ calculated respectively with load resistances equal to $R_{\text {Lopt }}$ or $R_{L \eta}$

$$
\begin{aligned}
& k_{\text {sopt }}=\frac{2\left(R_{1}+R_{\text {Lopt }} / 2\right)}{\sqrt{\frac{L_{a}}{C_{1}}\left(1-k_{m}^{2}\right)}\left(\sqrt{1+k_{m}}-\sqrt{1-k_{m}}\right)}=\frac{2\left(R_{1}+\sqrt{\frac{\left(C_{1} R_{1}^{2}+L_{a} k_{m}^{2}\right)}{C_{1}}}\right)}{\sqrt{\frac{L_{a}}{C_{1}}\left(1-k_{m}^{2}\right)}\left(\sqrt{1+k_{m}}-\sqrt{1-k_{m}}\right)} \\
& k_{s L \eta}=\frac{2\left(R_{1}+R_{L n} / 2\right)}{\sqrt{\frac{L_{a}}{C_{1}}\left(1-k_{m}^{2}\right)}\left(\sqrt{1+k_{m}}-\sqrt{1-k_{m}}\right)}=\frac{\left(2 R_{1}+\sqrt{\frac{\left(C_{1} R_{1}^{2}+L_{a} k_{m}^{2}\right)}{C_{1}}}\right)}{\sqrt{\frac{L_{a}}{C_{1}}\left(1-k_{m}^{2}\right)}\left(\sqrt{1+k_{m}}-\sqrt{1-k_{m}}\right)}
\end{aligned}
$$


In the following section the validity of the proposed criteria is numerically investigated and verified solving some benchmark test cases.

\section{Simulation results}

The proposed design method introduced in the previous section provides the following design criteria:

- $\quad$ system is designed (tuning of compensating capacities) to work with a exciting frequency equal to $\omega_{\text {opt }}$ as defined in equation (29)

- load $R_{L}$ is adjusted in order to verify the optimal design condition corresponding approximately to unitary value of $\boldsymbol{k}_{s}$.

The resulting design procedure is focused on two dimensionless factors: the merit coefficient $k_{m}$, which has to be maximised in order to improve magnetic coupling between coils, and $k_{s}$ which should be used to define an optimal loading resistance $R_{L}$ ensuring good efficiency for the input exciting frequency $\omega_{\text {opt }}$. Results obtained with the proposed approximated modal approach are compared with the ones calculated using a numerical model which solve the real test case ignoring any simplification. All the performed calculations and simulations have been performed in Matlab-Simulink ${ }^{\mathrm{TM}}$ environment. The benchmark system is shown in Figure 10.

Parameters of the lumped benchmark coils and of the corresponding series-series capacitive compensations are visible in Table 4. Adopted variables are the same as described in the lumped circuit scheme of Figure 5. Compensating capacities $C_{1}$ and $C_{2}$ are supposed to be equal and calculated to obtain a value of $\omega_{o p t}$ corresponding to $85 \mathrm{kHz}$. The lumped parameters describing the proposed test coils have been estimated in a previous work (Pugi et al., 2017). Since the proposed comparison should be influenced by the particular set of numerical values adopted in the benchmark some tests are performed considering some perturbed conditions.

Figure 10 Benchmark test coils adopted in this paper (see online version for colours)

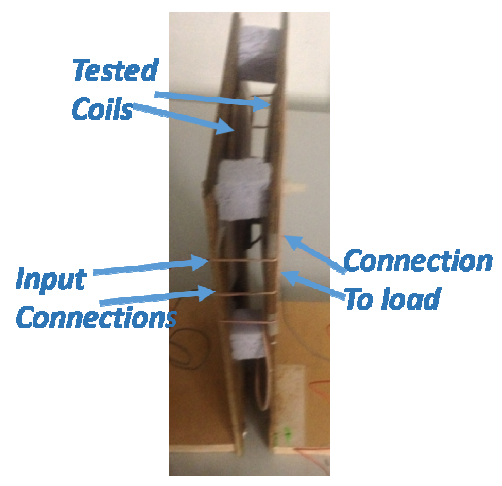

In particular, the value of the coil resistance is perturbed with known multiplicative factors obtaining the perturbed minimum and maximum perturbed values also described in Table 4. 
Table 4 Main features of the benchmark test case

\begin{tabular}{|c|c|c|c|c|c|}
\hline $\begin{array}{l}\text { Number of turns } \\
\text { of each coil }\end{array}$ & $\begin{array}{c}\text { Internal } \\
\text { Resistance of } \\
\text { coils: } R_{1}=R_{2} \\
\text { Min-Nominal- } \\
\quad \text { Max } \\
\end{array}$ & $\begin{array}{c}\text { Total Inductance } \\
L_{a}=L_{b}=L_{1}+M_{12}=L_{2}+M_{12} \\
\text { Comp.Capacity } \omega_{\text {opt }}\end{array}$ & $\begin{array}{c}\text { Internal } \\
\text { coil } \\
\text { diameter }\end{array}$ & $\begin{array}{c}\text { External } \\
\text { coil } \\
\text { diameter }\end{array}$ & $\begin{array}{c}\text { Explored } k_{m} \\
\text { range } \\
\text { (obtained } \\
\text { regulating } \\
\text { axial airgap } \\
\text { between } \\
\text { coils) } \\
\end{array}$ \\
\hline 18 & $\begin{array}{c}0.017-0.17- \\
1.7[\Omega]\end{array}$ & $\begin{array}{c}18[\mu \mathrm{H}] \\
0.195[\mu \mathrm{C}] \\
\approx 85[\mathrm{kHz}]\end{array}$ & $20[\mathrm{~mm}]$ & $90[\mathrm{~mm}]$ & $\begin{array}{c}\text { Range of } \mathrm{km} \\
\text { from } 0.1 \text { to } \\
0.9\end{array}$ \\
\hline
\end{tabular}

In Figure 11, some results concerning the response of the system in terms of transferred power $W_{L}$ with respect to the squared value of the input voltage $V_{l}$ are shown. The analysis is performed considering different values of the magnetic coupling factor $k_{m}$.

Results confirm the preliminary evaluations obtained using the proposed modal approach:

- There are two modes and eigen-frequencies which are clearly recognisable only for limited load values corresponding to low values of $\xi_{i}$ and consequently of $k_{s}$.

- The excitation of a single mode is associated to local maximums in the response surface which are located approximately for both frequencies at the same value of $k_{s}$.

- There is an absolute maximum in terms of response for input frequencies corresponding to $\omega_{\text {opt }}$. The value of $\omega_{\text {opt }}$ is independent from $k_{m}$. The value of $k_{s}$ that produce the maximum power transfer is roughly proportional to $k_{m}$.

Results of Figure 11 are useful to find maximum power transfer condition with respect to input voltage and frequency, however a comparison in terms of efficiency should be more useful: performances of the system are often limited by thermal loads due to losses on coils. As a consequence, maximum power transfer should be limited by the necessity of avoiding thermal overloads. If the load $R_{L}$ is optimised for efficiency, losses with respect to the transferred power are minimised.

Figure 11 Calculated specific power transfer for the benchmark example considering different magnetic coupling factors: (a) $\mathrm{km}=0.1$; (b) $\mathrm{km}=0.45$ and (c) $\mathrm{km}=0.9$ (see online version for colours)
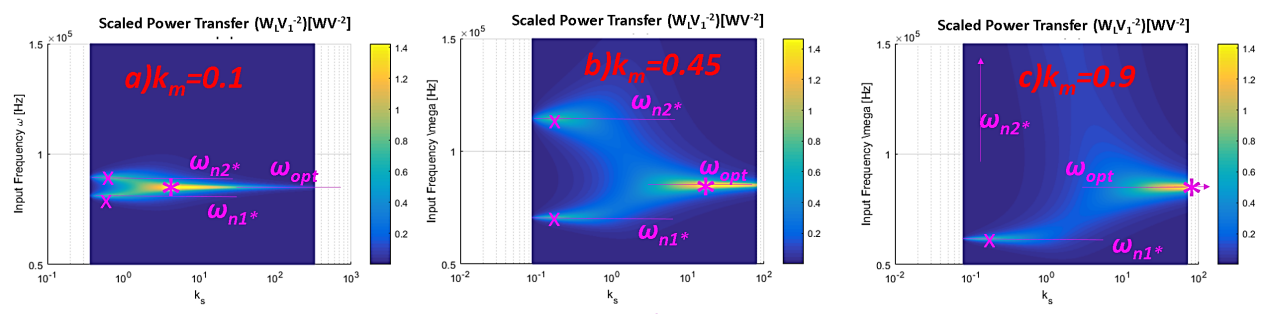

$x$ local maximum of transferred power (single mode excitation) $\quad *$ Absolute maximum of transferred power $\left(\omega_{o p t}\right)$

Maintaining the same value of $R_{L}$ and the same efficiency, there still the possibility of increasing transferred power $W_{L}$ since it's proportional to the squared value of $V_{l}$. As a 
consequence, a relatively small increase of the applied voltage should be used to increase power transfer without renouncing to an optimal efficiency.

For these reasons, same test cases of Table 4 calculations are repeated considering the evaluation of efficiency. Results are visible in Figures 12 and 13 and in Table 5:

- As visible in Figure 12 and Table 5, where efficiency behaviour is represented, it is preferable to work at frequency $\omega_{\text {opt }}$ especially for low values of $k_{m}\left(k_{m}=0.1\right)$. Efficiencies calculated considering the excitation of the resonance of a single mode are very low; so it is useless to excite separately a single resonant mode of the system. For high values of $k_{m}\left(k_{m}=0.45-0.9\right)$ good efficiency is also maintained with exciting frequencies higher than $\omega_{\text {opt }}$ which are penalised in terms of corresponding power transfer.

- Proposed design criteria corresponding to a unitary value of $k_{s}$ involve very good efficiencies which are very close to the maximum absolute value; this is very interesting considering that proposed design criteria was defined starting from an approximating system with proportional damping.

Results are shown in Figures 12 and 13 and in Table 5: maximum efficiency values are reached for values of $k_{s}$ which are reasonably near to one. Prediction is very good especially for low to medium values of $k_{m}(0.1-0.45)$; maximum efficiency points corresponds to values of $k_{s}$ which are only a bit higher respect to one. Also efficiency behaviour is quite flat for $k_{s}$ equal to one, hence the difference respect to the absolute optimum is very small. As a consequence, it should be deduced that proposed criteria are relatively robust respect to small fluctuations of system parameters. As an example, resistances of coils are supposed constant and known but also the thermal and skin effects on conductors should produce appreciable tolerances respect to nominal values.

- Same calculations are repeated considering different coil internal resistances as visible in Figure 13 It is clearly advisable that a unitary value of $k_{s}$ involves a better efficiency and fitting as internal coil resistances decrease. However as previously introduced, a good design of pad implies the minimisation of coil resistance in order to maximise efficiency. As a consequence, the proposed modal approach is more accurate for solutions which are more interesting from an industrial point of view. For high values of the internal coil resistance, a design based on the value of $k_{\text {sopt }}$ should produce more accurate results. On the other hand, the design of coils with very high resistance/inductance ratio has reduced industrial or scientific interest since the involved loss of efficiency should be unacceptable for any real application.

In order to prove the general validity of the proposed method, it has been applied to different coils whose main data are reported in (Zhong and Hui, 2015) and summarised in Table 6. In this case results are reported in Table 7 and in Figure 14. It is clearly advisable that most of the previously cited considerations are confirmed:

- A unitary value of $k_{s}$ represents a good choice for optimal design of the system for most of the cases of industrial interest.

- $\quad k_{\text {sopt }}$ represents the optimal load condition for the simplified equivalent system with proportional damping but, when applied to the real system, results are not reliable. The only exception is represented by coils with high values of the internal resistances, but this case has not practical interest. 
Figure 12 Mapping of calculated system efficiency $\eta$ for different coupling factors km (calculated for nominal coil resistance) (see online version for colours)
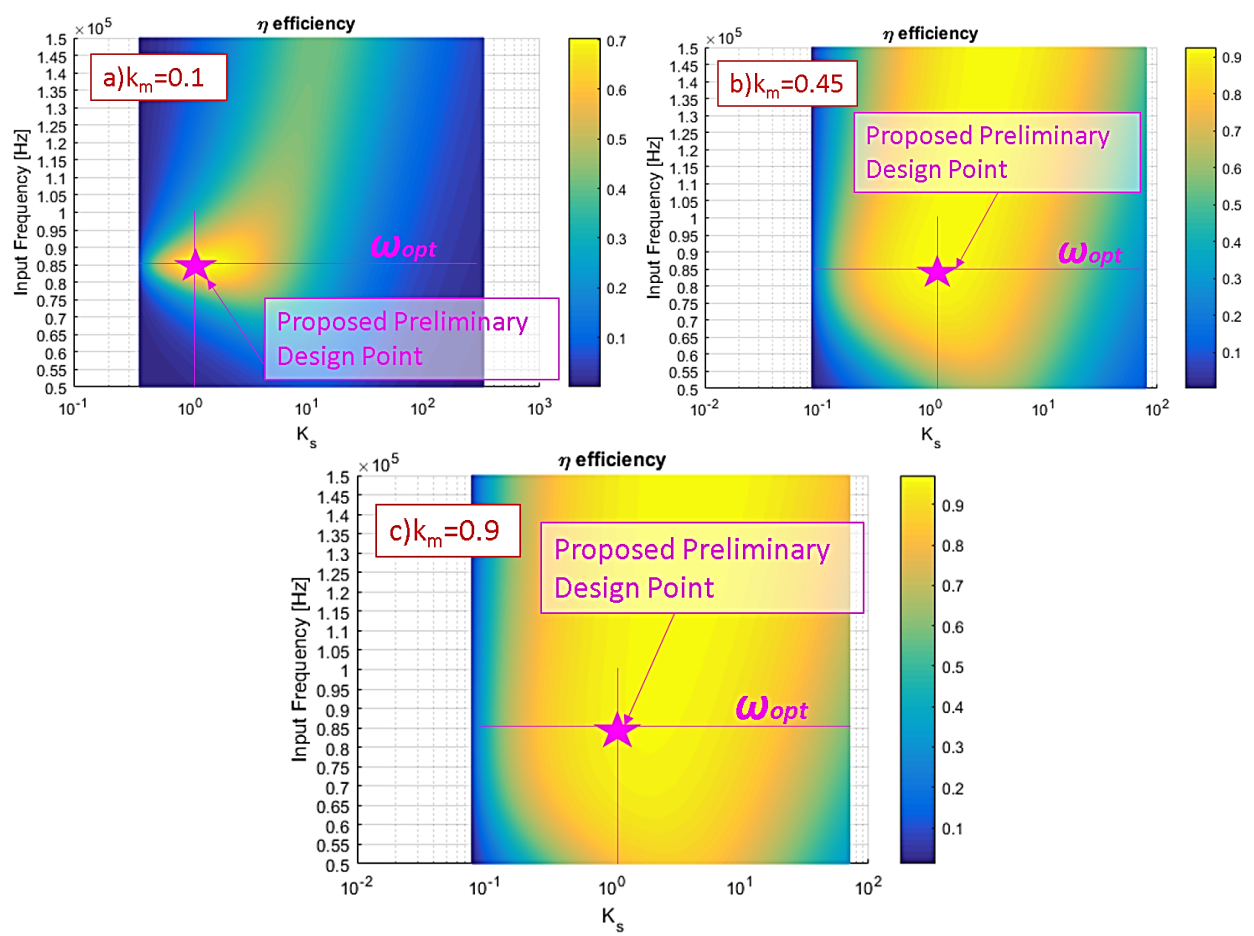

Figure 13 Calculated system efficiency $\eta$ (constant input frequency $\omega_{\text {opt }}=85 \mathrm{KHz}$ ) as function of $k_{m}$ and $R_{L}$ compared with different sizing criteria (see online version for colours)

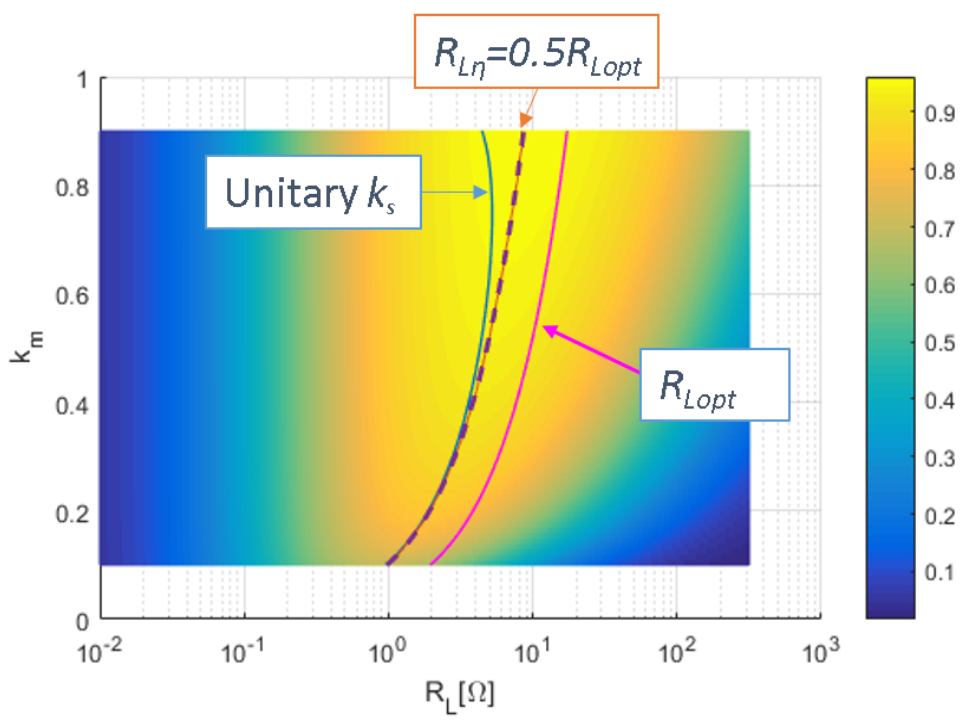


Table 5 Comparison of efficiency $\eta$ for different sizing criteria of $R_{L}$ (see online version for colours)

\begin{tabular}{|c|c|c|c|c|c|}
\hline Simulated $k_{m}$ & $\begin{array}{c}\text { Simulated Coil } \\
\text { Resistance }\end{array}$ & $\begin{array}{c}\text { Optimal } k_{s} \text { for } \\
\text { efficiency }{ }^{+}\end{array}$ & $\operatorname{Max} \eta$ & $\eta$ for $k_{s}=1$ & $\begin{array}{c}\eta \text { for } k_{\text {sopt }} \\
\text { (value of } k_{\text {sopt }} \text { ) }\end{array}$ \\
\hline 0.1 & $\begin{array}{l}\text { Nominal } \\
(0.17[\Omega])\end{array}$ & 1.406 & 0.703 & 0.685 & $0.662(2.4)$ \\
\hline 0.45 & $\begin{array}{l}\text { Nominal } \\
(0.17[\Omega])\end{array}$ & 1.15 & 0.924 & 0.923 & $0.91(2.3)$ \\
\hline 0.9 & $\begin{array}{l}\text { Nominal } \\
(0.17[\Omega])\end{array}$ & 1.96 & 0.961 & 0.9515 & $0.952(4.0)$ \\
\hline 0.1 & $\begin{array}{l}\text { Mininum } \\
(0.017[\Omega])\end{array}$ & $\begin{array}{c}1.03 \text { (not } \\
\text { appreciable) }\end{array}$ & 0.965 & 0.9652 & $0.96(2.2)$ \\
\hline 0.45 & $\begin{array}{l}\text { Mininum } \\
(0.017[\Omega])\end{array}$ & 1.23 & 0.992 & 0.9923 & $0.991(2)$ \\
\hline 0.9 & $\begin{array}{l}\text { Mininum } \\
(0.017[\Omega])\end{array}$ & 1.39 & 0.996 & 0.995 & $0.995(3.9)$ \\
\hline 0.1 & $\begin{array}{c}\text { Maximum } \\
(1.7[\Omega])\end{array}$ & 5.58 & $0.069 *$ & $\begin{array}{c}\text { Almost } \\
\text { null* }\end{array}$ & $0.062 *(7.6)$ \\
\hline 0.45 & $\begin{array}{c}\text { Maximum } \\
(1.7[\Omega])\end{array}$ & 2.035 & $0.464 *$ & $0.208^{*}$ & $0.424 *(3.2)$ \\
\hline 0.9 & $\begin{array}{c}\text { Maximum } \\
(1.7[\Omega])\end{array}$ & 2.76 & $0.676^{*}$ & $0.361 *$ & $0.635 *(4.7)$ \\
\hline
\end{tabular}

$\uparrow$ maximum efficiency obtained with a loading condition corresponding to $R_{L \eta}$.

*These results are introduced only to verify that a big increase of coil resistance lead to unacceptable penalisation of performances.

Table 6 Alternative test case taken from literature

\begin{tabular}{|c|c|c|c|c|c|}
\hline $\begin{array}{l}\text { Number of } \\
\text { turns of } \\
\text { each Coil }\end{array}$ & $\begin{array}{l}\text { Internal resistance of } \\
\quad \text { coils: } R_{1}=R_{2} \\
\text { Min-Nominal-Max }\end{array}$ & $\begin{array}{c}\text { Total Inductance } \\
L_{a}=L_{b}=L_{1}+M_{12}= \\
L_{2}+M_{12} \\
\text { Comp. Capacity } \\
\omega_{\text {opt }}\end{array}$ & $\begin{array}{l}\text { Internal } \\
\text { coil } \\
\text { diameter }\end{array}$ & $\begin{array}{c}\text { External } \\
\text { Coil } \\
\text { diameter }\end{array}$ & Corresponding $k_{m}$ \\
\hline $2 \times 9$ & $0.3[\Omega]$ & $\begin{array}{c}\text { About } 26[\mu \mathrm{H}] \\
\mathbf{0 . 1 0 6}[\boldsymbol{\mu C}] \\
\mathbf{9 6}[\mathbf{k H z}]\end{array}$ & $21.7[\mathrm{~mm}]$ & $27.02[\mathrm{~mm}]$ & $\begin{array}{l}\text { *In the paper } \\
\text { (Zhong and Hui, } \\
2015 \text { ) distance } \\
\text { between coils is } \\
\text { changed } \\
\text { producing a km of } \\
0.1 \text { and } 0.45\end{array}$ \\
\hline
\end{tabular}

Source: Zhong and Hui (2015)

\section{Preliminary FEM verification}

A FEM model of the axial coupled coils using ComsolTM multiphysics has been introduced in order to verify the performance of the proposed modelling approach. Since the coils under test (Zhang et al., 2006) are axial symmetric, also the corresponding 
model exploits this symmetry hypothesis to drastically reduce the computational load. Few planar elements are used with respect to a general three-dimensional formulation involving many three-dimensional finite elements. The coil wires are modelled in order to fit the real frequency behaviour previously measured in laboratory.

Table 7 Comparison of efficiency $\eta$ for different values

\begin{tabular}{lcccc}
\hline Simulated $k_{m}$ & $\begin{array}{c}\text { Optimal } k_{s} \text { for } \\
\text { efficiency }\end{array}$ & Max efficiency $\eta$ & $\begin{array}{c}\eta \text { for } \\
k_{s}=1\end{array}$ & $\begin{array}{c}\eta \text { for } k_{\text {sopt }} \\
\left(\text { value of } k_{\text {sopt }} \text { ) }\right.\end{array}$ \\
\hline 0.1 & 1.14 & 0.565 & 0.56 & $0.48(2.4)$ \\
0.45 & 0.92 & 0.876 & 0.875 & $0.824(2.3)$ \\
\hline
\end{tabular}

$k_{m}$ (calculated for nominal coil resistance).

Figure 14 Mapping of calculated system efficiency $\eta$ for different coupling factors (see online version for colours)
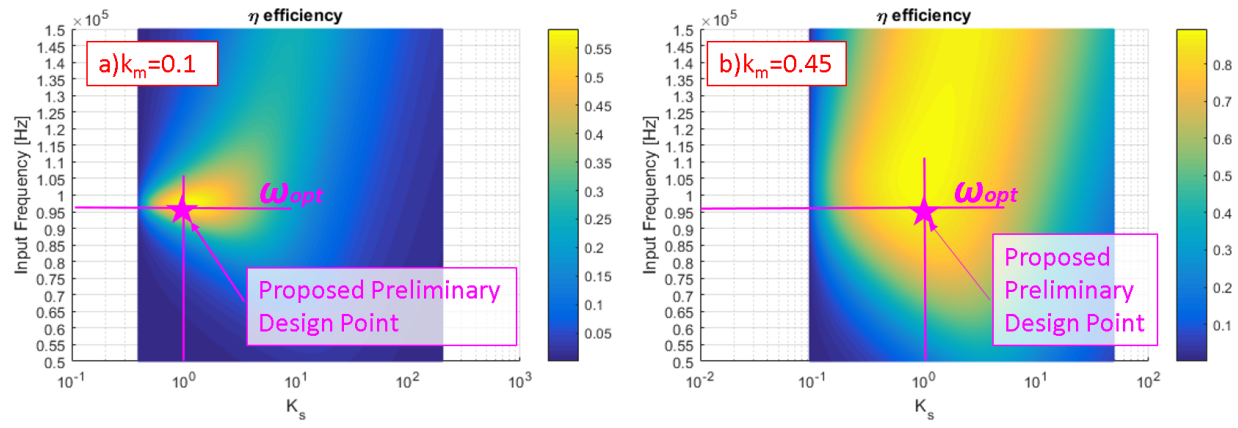

The two lumped coils are connected respectively to an alternating voltage source in series with a capacitor for the primary coil and to the load resistance $R_{L}$ in series to a capacitor for the secondary one. Coupled lumped circuit elements are also modelled since the same finite element environment offer the possibility of solving the electromagnetic coupling of coils with an equivalent ordinary differential equation (ODE) system adopting the solving scheme of Figures 15 and 16. As visible in Figure 16, the Comsol $^{\mathrm{TM}}$ model is composed by two parts which substantially corresponds to different implementations:

- Electromagnetic interaction of coils is solved using finite element method (FEM), at each computational step coils should be solved imposing as boundary conditions currents $I_{1}$ and $I_{2}$ (as visible in Figure 16(a)) or corresponding voltages applied to coils (as visible in Figure 16(b)). Both the approaches have been verified as fully working and able to converge to same results. FEM model is able to reproduce not only electro-magnetic interaction between coils but also internal conduction losses, being able to reproduce resistance variations due to skin-effect on cables or other interactions affecting current density on wires.

- The physical behaviour of coils is modelled using FEM method but the remaining part of coupled primary and secondary circuit (primary voltage source, compensating capacities, loads connected to the secondary pad) is modelled and solved as a lumped system implemented as ODE (Ordinary Differential Equations). ODE are solved by a dedicated solver which interacts at each computational step with the FEM one. For 
the scheme of Figure 16(a), ODE solver receives as input from the FEM model coil voltages calculated in a previous computational step, so corresponding currents in the two circuits can be calculated. Once currents are calculated they are imposed as new boundary conditions for the FEM model in the following computational step. For the scheme of Figure 16(b) the approach is similar but input and output are inverted: input for ODE solver are the coil currents calculated by the FEM solver corresponding voltage drops are calculated and imposed for next FEM computational step to the electro-magnetic model of coils.

Figure 15 Finite element model of the benchmark coils (see online version for colours)

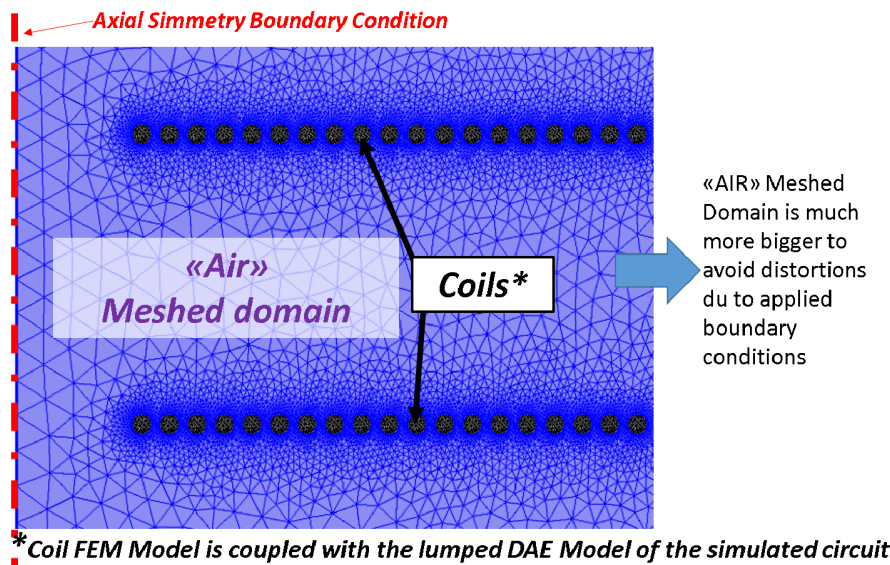

Figure 16 Coupling between FEM model of coils and corresponding connected lumped circuits: (a) scheme with current driven coils and (b) scheme with voltage driven coils (see online version for colours)

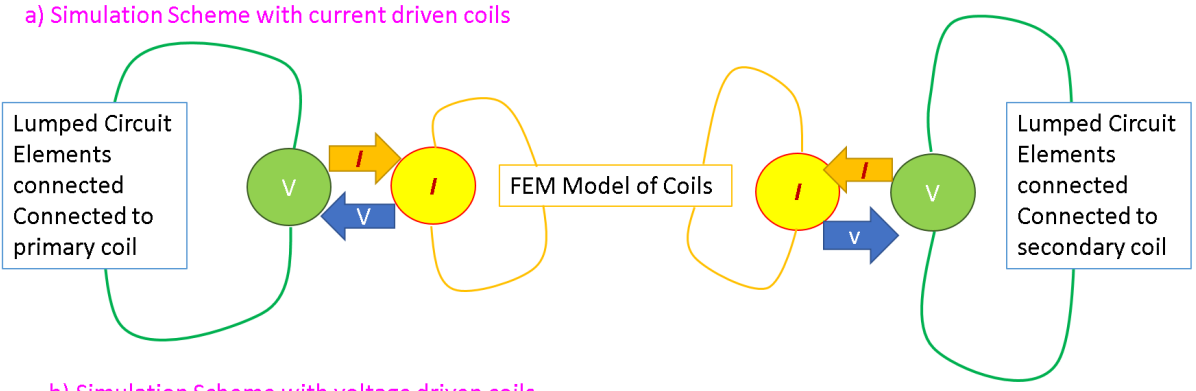

b) Simulation Scheme with voltage driven coils

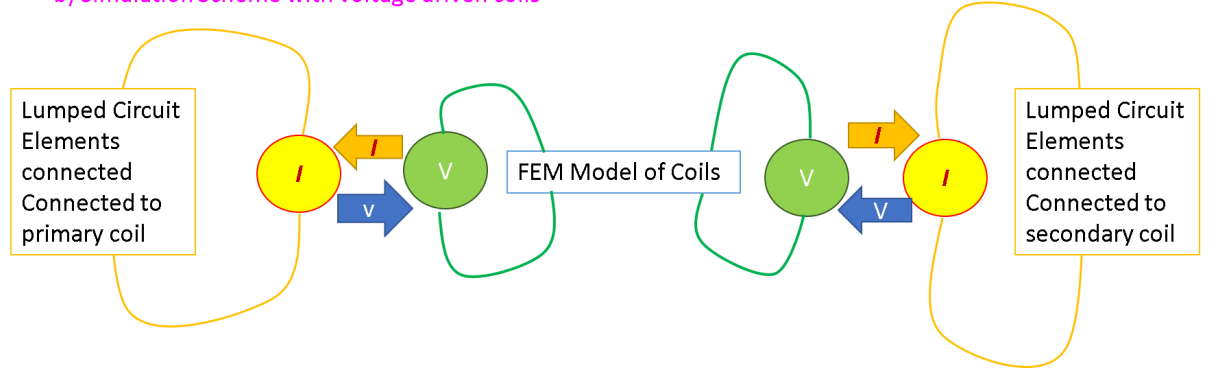


It's interesting to notice that proposed FEM model is able to reproduce the behaviour of the two modal shapes foreseen by the proposed modal approach: as visible in Figure 17, it is possible to recognise the shapes of the modes by properly simulating the forcing resonating frequencies of the coil with a low value of the load $R_{L}$ (very low damping applied to the system). In particular, it's clearly seen in Figure 17, the behaviour of the magnetic flux is substantially the expected one: for one mode currents are enforcing flux through coils, in the other one induced currents on secondary one are substantially cancelling/reducing flux oscillations. This behaviour corresponds approximately to a phase of about $0^{\circ}$ or $180^{\circ}$ degree between primary and secondary currents $\left(I_{1}\right.$ and $\left.I_{2}\right)$ as prescribed by the modal approach.

Figure 17 Preliminary verification of the modal shapes on comsol FEM models (distribution of induced field B when coil modes are excited separately) (see online version for colours)
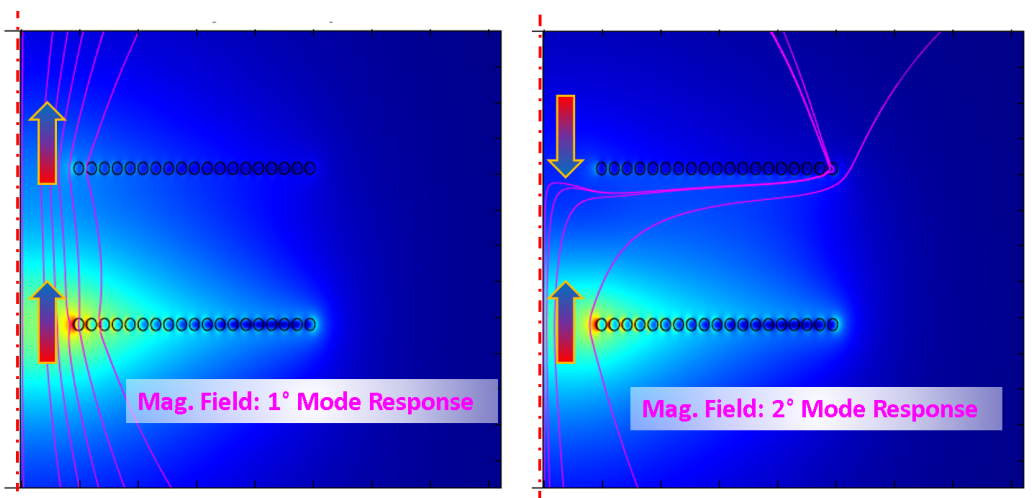

Results of FEM model are compared to results provided by the proposed method in terms of relative errors for different simulation conditions. Recorded errors between FEM and simulation with lumped model are almost negligible (less than $1 \%$ in most cases), hence the two models can be assumed as equivalent since there is almost no-difference in terms of results. Higher errors are recorded when comparing the FEM model results with the experimental ones as visible in Figure 18. Considering the proven equivalence between the FEM and lumped Matlab-Simulink ${ }^{\mathrm{TM}}$ models, these deviations should be ascribable to some imperfections of the experimental setup (coil assembly and alignment, electrical connections, neglected contributions of other connected components) and to measurement errors.

As a consequence, it's probably more interesting to focus future research activities on identifications and control techniques able to evaluate and, as a second step, mitigate the effects of tolerated/perturbed system parameters on its global performances.

In this sense the application of modal approach to IPT systems should be extended in future applications not only to modelling but also to system identification in case of uncertain or tolerated parameters: in particular exists a wide know-how of modal identification techniques (Zhao et al., 2015; Zhong et al., 2015; Zicheng et al., 2016) that should be applied to better identify damping and more generally features of the tested systems: for example classic impulse or sinusoidal input tests that are often performed on lightly damped mechanical structures should be customised to be automatically performed on an IPT to identify and calibrate the system in a very fast way considered 
that this kind of techniques have been developed to solve troubles that should be expected also on these applications:

- There is a strong physical analogy between vibrating mechanical system and electrical resonating ones, so there is an high probability that identification techniques originally developed for modal analysis should be used also for IPT systems.

- In both cases duration of tests is limited (in case of mechanical system testing is often a long expensive activity that have to be highly optimised).

- Measurements are affected by noise and disturbances (for large mechanical structures it's difficult to excite the system with precise waveform, and often it's difficult to reject noise due to external disturbances).

- It's more interesting to capture and fit the general response of the system in terms of frequency response (modes, damping factors etc.) respect to a precise identification of single parameters (e.g., it's more interesting to find a resonating frequency, and its amplification ratio than the set of perturbations on circuit parameters that have produced it).

- Finally, most of these modal identification techniques have been developed with a strong attention to numerical efficiency and robustness so they should be well suited for real time implementation, also considering continuous improvements in digital signal processing techniques.

Figure 18 Example of preliminary validation of FEM model respect to experimental results $\left(k_{m} \approx 0.35 \mathrm{R}_{\mathrm{L}}=1 \Omega\right)$ (see online version for colours)

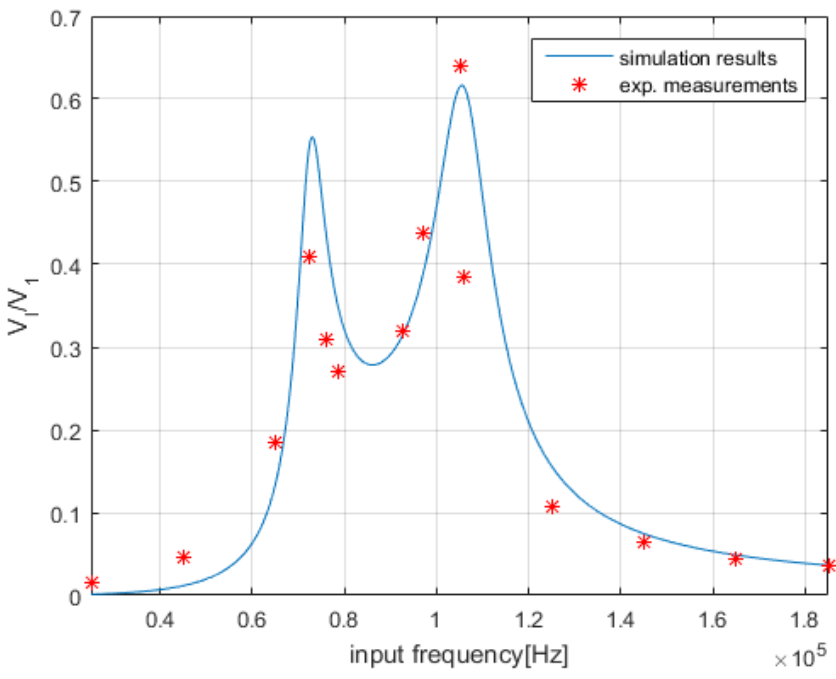

\section{Conclusions}

In this work an innovative approach for the wireless power transfer modelling is presented and based on an equivalent mechanical vibrating system model. Identification 
tools usually adopted for modal analysis and for the identification of vibrating/resonating mechanical systems are used.

The proposed approach is applied to a symmetric-equal coils system, leading to some useful and relatively original results. Considering that the behaviour of the equivalent vibrating system can be easily understood by applying the proportional damping hypothesis, the response of the system is decomposed with respect to a new system of coordinates (the modes) in the sum of two elementary decoupled resonating systems.

According the above introduced approach, optimal working conditions should be associated with a frequency in which both the modes in quadrature are excited and their response is reasonably high. The above described optimal condition can be approximately evaluated using the half power method, a simplified approach often used for the rough identification of modal damping in mechanical systems. Using the proposed methodology, it's also introduced a dimensionless parameter, "the weighted damping factor" briefly called $k_{s}$ that should be useful to parametrically optimise the load applied on secondary coil.

Proposed modal approach has been verified numerically and by comparing obtained results with the corresponding criteria suggested by more conventional methods found in literature. In both cases feasibility and accuracy of the proposed method are substantially confirmed. Identification, optimisation and control techniques of the wireless power transfer circuit based on the proposed electro-mechanical analogy could represent further developments of the proposed approach.

\section{References}

Alfatihi, S., Chihab, S. and Alj, Y.S. (2013) 'Intelligent parking system for car parking guidance and damage notification', 4th International Conference on Intelligent Systems, Modelling \& Simulation, 29-31 January, 2013, Bangkok, pp.24-29.

Borutzky, W. (2010) Bond Graph Methodology, Springer, Berlin, ISBN 978-1-84882-881-0.

Budhia, M., Covic, G.A. and Boys, J.T. (2011) 'Design and optimization of circular magnetic structures for lumped inductive power transfer systems', IEEE Transactions on Power Electronics, Vol. 26, No. 11, November, pp.3096-3108.

Bululukova, D. and Kramer, M. (2014) 'Application of existing wireless power transfer standards in automotive applications', 2014 International Conference on Connected Vehicles and Expo (ICCVE), IEEE, 3-7 November, 2014, Vienna, Austria, pp.863-864.

Covic, G.A. and Boys, J.T. (2013a) 'Modern trends in inductive power transfer for transportation applications', IEEE J. Emerg Sel Topics Power Electron, Vol. 1, No. 1, pp.28-41.

Covic, G.A. and Boys, J.T. (2013b) 'Inductive power transfer', Proceedings of the IEEE, Vol. 101, No. 6, pp.1276-1289.

Ewins, D.J. (1984) Modal Testing: Theory and Practice, Vol. 15, Research Studies Press, Letchworth.

Fu, Z-F. and He, J. (2001) Modal Analysis, Butterworth-Heinemann, London.

Jiang, K. and Seneviratne, L.D. (1999) 'A sensor guided autonomous parking system for nonholonomic mobile robots', ICRA 99 International Conference on Robotics and Automation, 10-15 May, 1999, Detroit, MI, USA,

Karnopp, D.C., Margolis, D.L. and Rosenberg, R.C. (1990) System Dynamics: A Unified Approach, Wiley, ISBN 0-471-62171-4.

Kim, D., Chung, W. and Park, S. (2010) 'Practical motion planning for car-parking control in narrow environment', IET Control Theory and Applications, Vol. 4, No. 1, pp.129-139. 
Pugi, L., Conti, R., Nocciolini, D., Galardi, E., Rindi, A. and Rossin, S. (2014) 'A tool for the simulation of turbo-machine auxiliary lubrication plants', International Journal of Fluid Power, Vol. 15, No. 2, pp.87-100.

Pugi, L., Galardi, E., Carcasci, C., Rindi, A. and Lucchesi, N. (2015) 'Preliminary design and validation of a real time model for hardware in the loop testing of bypass valve actuation system', Energy Conversion and Management, Vol. 92, pp.366-384.

Pugi, L., Malvezzi, M., Allotta, B., Banchi, L. and Presciani, P. (2004) 'A parametric library for the simulation of a union internationale des chemins de fer (UIC) pneumatic braking system', Proceedings of the Institution of Mechanical Engineers, Part F: Journal of Rail and Rapid Transit, Vol. 218, No. 2, pp.117-132.

Pugi, L., Reatti, A., Corti, F. and Mastromauro, R.A. (2017) 'Inductive power transfer: through a bondgraph analogy, an innovative modal approach', IEEE EEIC 2017 Conference, 7-9 June, Milan Italy.

SAE TIR J2954 (2016) Wireless Power Transfer for Light-Duty Plug-In/Electric Vehicles and Alignment Methodology.

Shabana, A.A. (1996) Theory of Vibration, An Introduction Springer, New York, USA.

Stephen, N.G. (2006) 'On the maximum power transfer theorem within electromechanical systems', Proceedings of the Institution of Mechanical Engineers, Part C: Journal of Mechanical Engineering Science, Vol. 220, No. 8, pp.1261-1267.

Zhang, X., Ho, S.L. and Fu, W.N. (2016) 'Quantitative analysis of a wireless power transfer cell with planar spiral structures', IEEE Transactions on Magnetics, Vol. 47, No. 10, pp.3200-3203.

Zhao, L., Thrimawithana, D.J., Madawala, U.K. and Baguley, C.A. (2015) 'Performance optimization of LC bi-directional inductive power transfer system', IEEE 13th Brazilian Power Electronics Conference and 1 st Southern Power Electronics Conference (COBEP/SPEC), pp.1-6.

Zhong, W.X. and Hui, S.Y.R. (2015) 'Maximum energy efficiency tracking for wireless power transfer systems', IEEE Transactions on Power Electronics, Vol. 30, No. 7, pp.4025-4034.

Zicheng, B., Kan, T., Mi, C.C., Zhang, Y., Zhao, Z. and Keoleian, G.A. (2016) 'A review of wireless power transfer for electric vehicles: prospects to enhance sustainable mobility', Applied Energy, Vol. 179, pp.413-425. 